\title{
Poly- $\gamma$-Glutamic Acid Complexed With Alum Induces Cross-Protective Immunity of Pandemic H1N1 Vaccine
}

\author{
Quyen Thi Nguyen 1,2†, Chaewon Kwak ${ }^{1,2 t}$, Wang Sik Lee ${ }^{3,4}$, Jaemoo Kim 1,2, \\ Jinyoung Jeong ${ }^{3,4}$, Moon Hee Sung ${ }^{5}$, Jihyun Yang ${ }^{1 *}$ and Haryoung Poo ${ }^{1,2 *}$
}

${ }^{1}$ Infectious Disease Research Center, Korea Research Institute of Bioscience and Biotechnology, Daejeon, South Korea, ${ }^{2}$ Department of Biosystems and Bioengineering, KRIBB School of Biotechnology, University of Science and Technology, Daejeon, South Korea, ${ }^{3}$ Environmental Disease Research Center, Korea Research Institute of Bioscience and Biotechnology, Daejeon, South Korea, ${ }^{4}$ Department of Nanobiotechnology, KRIBB School of Biotechnology, University of Science and Technology, Daejeon, South Korea, ${ }^{5}$ Department of Bio and Nanochemistry, Kookmin University, Seoul, South Korea

\section{OPEN ACCESS}

Edited by:

Babita Agrawal,

University of Alberta, Canada

Reviewed by:

Ji Wang,

Sun Yat-sen University, China Raffael Nachbagauer, Icahn School of Medicine at Mount

Sinai, United States

*Correspondence:

Jihyun Yang

jhyang@kribb.re.kr

Haryoung Poo

haryoung@kribb.re.kr

tThese authors have contributed equally to this work

Specialty section:

This article was submitted to

Vaccines and Molecular Therapeutics,

a section of the journal

Frontiers in Immunology

Received: 12 April 2019 Accepted: 27 June 2019

Published: 11 July 2019

Citation: Nguyen QT, Kwak C, Lee WS, Kim J, Jeong J, Sung $M H$, Yang $J$ and Poo $H$ (2019) Poly- $\gamma$-Glutamic Acid Complexed With Alum Induces Cross-Protective Immunity of Pandemic H1N1 Vaccine.

Front. Immunol. 10:1604. doi: 10.3389/fimmu.2019.01604
The use of a good vaccine adjuvant may induce a higher immunogenicity profile of vaccine antigens. Here, we developed a new adjuvant by combining poly- $\gamma$-glutamic acid ( $\gamma$-PGA) with alum (PGA/Alum) and investigated its ability to enhance the immunogenicity and the cross-reactive efficacy of pandemic $\mathrm{H} 1 \mathrm{~N} 1$ (pH1N1) influenza vaccine antigen. PGA/Alum enhanced antigen delivery to draining lymph nodes and antigen-specific immunogenicity in mice using OVA as a model antigen. It also greatly increased OVA-specific antibody production, cytotoxic $T$ lymphocyte (CTL) activity, and antibody-dependent cellular cytotoxicity (ADCC). These abilities of PGA/Alum improved the protective efficacy of pH1N1 vaccine antigen by increasing hemagglutination-inhibition titers, enhancing ADCC and CTL activity, and speeding viral clearance following homologous viral challenge. Importantly, the cross-protective efficacy of pH1N1 vaccine against heterologous viruses [A/Puerto Rico/8/34 (H1N1) and A/Hong Kong/1/1968 (H3N2)] was significantly enhanced by PGA/Alum, and cross-reactive ADCC and CTL activities were observed. Together, our results strongly suggest that PGA/Alum may be a promising vaccine adjuvant for preventing influenza and other infectious diseases.

Keywords: vaccine adjuvant, influenza virus, efficacy, cross-protection, antibody-dependent cellular cytotoxicity, cytotoxic T lymphocyte activity

\section{INTRODUCTION}

Traditional vaccines are composed of killed or attenuated viruses or bacteria and have several drawbacks, including safety concerns, the need for complicated culture of the infectious agents, and the low yields of their manufacturing processes $(1,2)$. To solve these problems, researchers have developed new types of vaccine such as subunit recombinant vaccines and DNA vaccines (3). Unfortunately, most of these vaccines are unable to generate sufficient antigen-specific immunogenicity to effectively prevent infectious diseases. In particular, influenza continues to occur as a seasonal epidemic and in sporadic pandemics with considerable morbidity and mortality worldwide, largely because we lack an effective vaccine capable of inducing broad cross-protection against newly emerging influenza viruses that underwent antigenic drift and shift (4). The future development of effective influenza vaccines has been proposed to hinge on the use of adjuvants that improve the immunogenicity and cross-reactive immunity of vaccine antigens $(5,6)$. 
Despite extensive research, relatively few adjuvants have been licensed for use with human vaccines. These adjuvants included aluminum salts (alum) and emulsions (e.g., MF59) $(6,7)$. Since the $1920 \mathrm{~s}$, alum has been used as a vaccine adjuvant for a wide range of vaccines in the US and Europe. It can trigger robust humoral immune responses (i.e., antibody production), but does little to enhance the antibody-dependent cellular cytotoxicity (ADCC) and cytotoxic T lymphocyte (CTL) activities that are critical for the protection against various pathogens, including viruses and intracellular pathogens, and cross-reactivity against heterologous influenza viruses (8-11). Regarding MF59, its adjuvanted influenza vaccine did not show any significant difference in the cross-reactivity compared to the unadjuvanted vaccine (12), and MF59 itself has been associated with adverse effects, including injection site pain and the induction of inflammatory arthritis (13).

The current approach for developing vaccine adjuvants is based on our knowledge of the innate immune responses that initiate adaptive immune responses. Some adjuvants include agonists that can enhance innate immune responses through pattern recognition receptors, such as toll-like receptors (TLRs) $(14,15)$. Poly- $\gamma$-glutamic acid $(\gamma$-PGA) is a natural, biodegradable, and edible biopolymer composed of repeating units of both $\mathrm{D}$ - and L-glutamic acids combined via $\gamma$-amide linkages that is secreted naturally by the Bacillus subtilis sups. Chungkookjang commonly found in Korean traditional soybean paste, chungkookjang (16). We previously reported that $\gamma$ PGA induces TLR4-mediated innate immune responses and robustly provokes Th1 immune responses to enhance CTL activity (17). Taking advantage of the safety and potential immunostimulatory properties of $\gamma$-PGA, we developed a vaccine adjuvant by combining $\gamma$-PGA with alum (PGA/Alum) to resolve the limitations of currently licensed vaccine adjuvants. We investigated the physiochemical properties, efficacy, and action mechanisms of PGA/Alum using the model antigen, ovalbumin (OVA), in vivo and in vitro. We then evaluated the adjuvant efficacy of PGA/Alum in improving pandemic H1N1 (pH1N1) influenza vaccine antigen-specific cellular immune responses, antibody $(\mathrm{Ab})$ production, and crossreactivity against heterologous influenza A viruses. Our results demonstrate that PGA/Alum increased dendritic cell (DC) activation and antigen trafficking, thereby enhancing adaptive immune responses, particularly antigen-specific CTL activity and ADCC. Furthermore, the protective and cross-reactive efficacies of pH1N1 influenza vaccine were substantially improved by PGA/Alum, which conferred cross-protection accompanied with cross-reactive ADCC and CTL activities. Together, our results strongly suggest that PGA/Alum may be a promising vaccine adjuvant for prevention of influenza-related and other infectious diseases.

\section{MATERIALS AND METHODS}

\section{Mice}

Six- to eight-week-old female C57BL/6 mice (Orient Bio) were housed in a specific pathogen-free (SPF) facility in the Korea Research Institute of Bioscience and Biotechnology
(KRIBB). Handling of mice and experimental procedures were reviewed and approved by the Institutional Animal Care and Use Committee (IACUC) of the KRIBB (KRIBB-AEC-17013 and KRIBB-AEC-17162) and were performed according to the Guidelines for Animal Experiments of the KRIBB.

\section{Cells}

Bone marrow-derived DCs (BMDCs) were generated and maintained in RPMI 1640 (Gibco) that contained 10\% heatinactivated FBS (Gibco), $100 \mathrm{U} / \mathrm{ml}$ penicillin, and $100 \mathrm{mg} / \mathrm{ml}$ streptomycin (Gibco), as previously described (18). B16F10 and MDCK cells were purchased from ATCC and maintained in DMEM (Gibco) that contained 10\% heat-inactivated FBS, 100 $\mathrm{U} / \mathrm{ml}$ penicillin, and $100 \mathrm{mg} / \mathrm{ml}$ streptomycin. B16mOVA cells (B16F10 cells expressing membrane-bound OVA) were kindly provided by Dr. David J. Mooney (Harvard University, USA) and were maintained in DMEM supplemented with $10 \%$ heatinactivated FBS, $100 \mathrm{U} / \mathrm{ml}$ penicillin, $100 \mathrm{mg} / \mathrm{ml}$ streptomycin, and $1 \mu \mathrm{g} / \mathrm{ml}$ puromycin dihydrochloride (Millipore).

\section{Preparation of PGA/Alum}

PGA/Alum was prepared by combining $\gamma$-PGA (BioLeaders) and Imject alum (Thermo Fisher) in a $0.9 \%$ saline solution. Briefly, $1 \mathrm{mg} / \mathrm{ml}$ alum solution, $\mathrm{pH} 6.5$ (adjusted by $\mathrm{HCl}$ ) was added drop-wise into $1 \mathrm{mg} / \mathrm{ml} \gamma$-PGA solution, $\mathrm{pH} 6.8$ (adjusted by ammonia solution) $(\mathrm{v}: \mathrm{v}=1: 1)$ with constant stirring at $70 \times$ $g$. The resultant PGA/Alum was collected by centrifugation at $15,000 \times g$ for $30 \mathrm{~min}$ at $4^{\circ} \mathrm{C}$, re-suspended in a $0.9 \%$ saline solution, and stored at $4^{\circ} \mathrm{C}$ prior to use.

\section{Preparation of Viruses}

The influenza viruses A/California/04/09 (pH1N1), A/Puerto Rico/8/34 (H1N1), and A/Hong Kong/1/68 [H3N2 (a reassortant $\mathrm{H} 3 \mathrm{~N} 2$ virus carrying the $\mathrm{HA}$ and $\mathrm{NA}$ genes from $\mathrm{A} /$ Hong Kong/1/68 and internal genes from A/Puerto Rico/8/34)], were grown in 9 to 10 -day-old SPF embryonated chicken eggs (Orient Bio) for $48 \mathrm{~h}$ at $37^{\circ} \mathrm{C}$. The viruses were harvested from the allantoic fluids by centrifugation at 3,500 $\times$ $g$ for $10 \mathrm{~min}$ at $4^{\circ} \mathrm{C}$ and filtration through $0.45 \mu \mathrm{m}$ pore-size membrane filter (Millipore) and then stored at $-80^{\circ} \mathrm{C}$ until use. All viral experiments were performed under biosafety level $2+$ (BSL2+) conditions.

\section{Dynamic Light Scattering (DLS)}

The hydrodynamic diameter and polydispersity index of alum and PGA/Alum were measured using a particle-size analyzer (ELS-Z; Otsuka Inc.). Zeta-potential values were measured with a Zeta-sizer (Nano ZS; Malvern Instruments Ltd.).

\section{Scanning Electron Microscopy (SEM)}

The morphologies of alum and PGA/Alum were observed using a field-emission scanning electron microscope (FE-SEM, Quanta 250 FEG). Briefly, alum and PGA/Alum $(100 \mu \mathrm{g} / \mathrm{ml}, 1 \mathrm{ml})$ were dispersed in autoclaved saline buffer, dropped and dried on a silicon wafer, coated with gold for $60 \mathrm{~s}$ using a Polaron SC7640 sputter coater (Quorum Technologies Ltd.) and then subjected to SEM. 


\section{Transmission Electron Microscopy (TEM)}

TEM images of alum and PGA/Alum were obtained using a field-emission transmission electron microscope (FE-TEM; JEOL Ltd.). For visualization, alum and PGA/Alum $(100 \mu \mathrm{g} / \mathrm{ml})$ solutions were dropped and dried on a formvar- and carboncoated copper grid (Ted Pella, Inc).

\section{Fourier Transform Infrared (FT-IR) Spectroscopy}

To analyze the chemical structure of PGA/Alum, we performed FT-IR analysis using FT-IR spectroscopy (Alpha-T; Bruker Optics). Alum and PGA/Alum solutions (1 $\mathrm{mg} / \mathrm{ml}$ in saline buffer) were centrifuged at $10,000 \times g$ for $5 \mathrm{~min}$ and re-dispersed in distilled water. After all solutions were dried under a vacuum for 2 days, the powder was mixed with potassium bromide $(\mathrm{KBr})$. FT-IR signals were obtained by scanning from 500 to $4,000 \mathrm{~cm}^{-1}$ with a scan resolution of $4 \mathrm{~cm}^{-1}$.

\section{Determination of OVA Antigen Loading}

PGA/Alum and alum (10 $\mathrm{mg} / \mathrm{ml}$ each) were mixed overnight with OVA antigen $\left(3 \mathrm{mg} / \mathrm{ml}\right.$; Sigma-Aldrich) at $4^{\circ} \mathrm{C}$ with constant rotation at $15 \times g$. The resulting PGA/Alum-OVA complexes were centrifuged at $14,000 \times g$ for $15 \mathrm{~min}$, and the supernatants were collected for the analysis of unloaded OVA. The amount of loaded OVA was calculated based on the amount of unloaded OVA in the supernatants, as assessed via BCA protein assay (Pierce).

\section{Cell Viability Assay}

Immature BMDCs were generated from bone marrow cells of C57BL/6 mice and stimulated with alum, $\gamma$-PGA, or PGA/Alum at $25,50,100$, or $200 \mu \mathrm{g} / \mathrm{ml}$ for $24 \mathrm{~h}$. The cell viability was measured using the Cell Counting Kit-8 (Dojindo Laboratories) according to the manufacturer's instructions.

\section{In vitro Activation and Antigen Uptake/Processing of BMDCs}

To investigate BMDC activation, we stimulated the cells with $100 \mu \mathrm{g} / \mathrm{ml}$ alum, $100 \mu \mathrm{g} / \mathrm{ml} \gamma$-PGA, or $200 \mu \mathrm{g} / \mathrm{ml} \mathrm{PGA/Alum}$ for $24 \mathrm{~h}$ at $37^{\circ} \mathrm{C}$. To examine the antigen uptake and processing of BMDCs, we incubated the cells with either $5 \mu \mathrm{g} / \mathrm{ml} \mathrm{FITC-}$ OVA (Thermo Fisher) or $5 \mu \mathrm{g} / \mathrm{ml}$ DQ-OVA (a self-quenching conjugate of OVA that exhibits bright green fluorescence upon proteolytic degradation; Thermo Fisher) mixed with or without alum, $\gamma$-PGA, or PGA/Alum for 1 or $5 \mathrm{~h}$ at $37^{\circ} \mathrm{C}$, respectively.

\section{ELISA}

The cytokine levels in the culture supernatants were measured using ELISA kits (BD Bioscience) according to the manufacturer's instructions. To determine the levels of antigen-specific IgG $\mathrm{Ab}$ in the sera of immunized mice, ELISA plates (Nunc) were coated overnight with $1 \mu \mathrm{g} / \mathrm{ml}$ OVA protein or $0.5 \mu \mathrm{g} / \mathrm{ml}$ influenza vaccine antigen (A/California/7/2009 NYMC X-179A H1N1; provided by Mogam Biotechnology Research Institute) in carbonate solution, $\mathrm{pH} 9.5$, at $4^{\circ} \mathrm{C}$. ELISA was performed as previously described $(18,19)$.

\section{Flow Cytometry}

All cells were blocked with anti-CD16/CD32 monoclonal $\mathrm{Ab}(\mathrm{mAb})$ and stained with the subsequently described fluorochrome-conjugated mAbs. The mAbs were purchased from BD Biosciences, BioLegend, or eBioscience. To measure DC activation, cells were stained with $\mathrm{PE}$-conjugated $\mathrm{mAbs}$ against mouse CD40, CD80, CD86, MHC class II molecules or isotypematched control mAbs. To examine the proportions of DCs located at the injection sites and draining lymph nodes (dLNs), C57BL/6 mice were intramuscularly (i.m.) immunized with $5 \mu \mathrm{g}$ Alexa Fluor 647-conjugated OVA mixed with or without $800 \mu \mathrm{g}$ PGA/Alum, and cells were obtained after 3, 6, 12, and $48 \mathrm{~h}$ postimmunization. In other experiments, C57BL/6 mice were i.m. immunized with $5 \mu \mathrm{g}$ Alexa Fluor 647-conjugated OVA alone or mixed with $400 \mu \mathrm{g}$ alum, $400 \mu \mathrm{g} \gamma$-PGA, or $800 \mu \mathrm{g}$ PGA/Alum, and cells were obtained after $24 \mathrm{~h}$ post-immunization. The cells were stained with APC eFluor 780-conjugated anti-CD11c and Alexa Fluor 488-conjugated anti-MHC class II mAbs. To measure frequency of $\mathrm{OVA}_{257-264}$ tetramer-positive $\mathrm{CD} 8^{+} \mathrm{T}$ cells, splenocytes were obtained from the immunized mice and blocked with clear back ( $\mathrm{Fc}$ receptor blocking reagent; $\mathrm{MBL}$ ), stained with PE-conjugated $\mathrm{H}-2 \mathrm{~K}^{\mathrm{b}}$ OVA tetramer and FITCconjugated CD8 mAbs (MBL). All stained cells were acquired on FACSCalibur or FACSVerse flow cytometers (BD), and the data were analyzed using FlowJo software (Tree Star). Fluorescence compensation was optimized using cells individually labeled with each fluorochrome-conjugated $\mathrm{mAb}$. Data were obtained from the live population based on cell size- and morphology-based gating, which was used to eliminate cell debris and dead cells.

\section{In vivo Fluorescence Imaging}

To visualize the migration of antigen to the dLNs, a fluorescent dye-labeled antigen was prepared by conjugating $1 \mathrm{mg}$ OVA protein with $0.1 \mathrm{mg}$ IRDye800CW fluorescent dye using an IRDye800CW protein labeling kit (LI-COR Bioscience). The concentration of the resulting IRDye800CW-labeled OVA (OVAIR800) was determined using a BCA protein assay. Hair on the left forepaw and the dorsal skin of C57BL/6 mice were removed by applying depilatory creams (VEET Hair Removal Cream; Reckitt Benckiser Japan) for efficient signal transmission. The mice were anesthetized with $3 \%$ isoflurane and intradermally administered $25 \mu \mathrm{g}$ OVA-IR800 alone or mixed with $400 \mu \mathrm{g}$ alum, $400 \mu \mathrm{g} \gamma$-PGA, or $800 \mu \mathrm{g}$ PGA/Alum into the forepaw pad. At $1,3,6,24$, and $48 \mathrm{~h}$ post-injection, in vivo near-infrared (NIR) fluorescent signals from the anesthetized mice were acquired using the in vivo Imaging System (IVIS Lumina II; Xenogen Corp.) with excitation at $780 \mathrm{~nm}$ and emission at $831 \mathrm{~nm}$ at a $0.02 \mathrm{~s}$ exposure time. The fluorescent signals of OVA-IR800 in the axillary lymph node were quantitatively analyzed using image analysis Image software (NIH).

\section{Immunizations and Viral Challenge}

Animals were randomly distributed to groups of 3-6 mice. C57BL/6 mice were i.m. immunized with $10 \mu \mathrm{g}$ OVA in the presence or absence of $400 \mu \mathrm{g} / \mathrm{ml} \gamma$-PGA, $400 \mu \mathrm{g} / \mathrm{ml}$ alum, or $800 \mu \mathrm{g} / \mathrm{ml}$ PGA/Alum on days 0,14 , and 28. Spleens, bone marrow cells, and sera were collected on days 14 and 
180 after the last immunization. In a separate experiment, mice were i.m. immunized with the $\mathrm{pH} 1 \mathrm{~N} 1$ split vaccine antigen (A/California/7/2009 NYMC X-179A H1N1), which contained $0.05 \mu \mathrm{g}$ (for homosubtypic protection) or $0.5 \mu \mathrm{g}$ (for heterosubtypic protection) hemagglutinin (HA) plus 400 $\mu \mathrm{g} \gamma$-PGA, $400 \mu \mathrm{g}$ alum, or $800 \mu \mathrm{g}$ PGA/Alum on days 0 and 14. Spleens and sera were collected on day 14 after the last vaccination. Two weeks after the last vaccination, the mice were intranasally challenged with a lethal dose (LD) of influenza viruses, including $50 \mathrm{LD}_{50}$ (equivalent to 30,000 TCID $_{50}$ or 15,000 PFU) A/California/04/09 (pH1N1), 10 LD $_{50}$ (equivalent to $20 \mathrm{TCID}_{50}$ or $200 \mathrm{PFU}$ ) A/Puerto Rico/8/34 (H1N1), or $10 \mathrm{LD}_{50}$ (equivalent to $600 \mathrm{TCID}_{50}$ or $300 \mathrm{PFU}$ ) $\mathrm{H} 3 \mathrm{~N} 2$ viruses.

The body weight and survival were monitored for 14 days after the viral challenge. Mice that lost $>20 \%$ (for homosubtypic viral challenge) or $25 \%$ (for heterosubtypic viral challenge) of their body weight were considered to have reached the experimental end point and were sacrificed.

\section{Antibody-Dependent NK Cell Activation}

To examine the ability of the sera Abs of immunized mice to activate NK cells, we coated ELISA plates (Nunc) overnight at $4^{\circ} \mathrm{C}$ with $10 \mu \mathrm{g} / \mathrm{ml}$ OVA protein or $6 \mu \mathrm{g} / \mathrm{ml}$ influenza HA antigen that contained the stalk domain. The plates were washed with PBS, incubated with heat-inactivated sera $\left(1 \mathrm{~h}\right.$ at $\left.56^{\circ} \mathrm{C}\right)$ for $2 \mathrm{~h}$ at $37^{\circ} \mathrm{C}$, and washed with $\mathrm{PBS}$ to remove unbound serum Abs. NK cells were isolated from the splenocytes of unimmunized C57BL/6 mice using a NK cell isolation kit (Miltenyi Biotec). The isolated NK cells were dispensed to the ELISA plates $\left(1 \times 10^{5}\right.$ cells/well $)$ and incubated in the presence of PE-conjugated anti-CD107a mAb, $5 \mu \mathrm{g} / \mathrm{ml}$ brefeldin $\mathrm{A}$, and $5 \mu \mathrm{g} / \mathrm{ml}$ monensin for $5 \mathrm{~h}$ at $37^{\circ} \mathrm{C}$. Finally, the NK cells were harvested, fixed, permeabilized, and intracellularly stained with APC-conjugated anti-IFN- $\gamma$ using a Cytofix/Cytoperm kit (BD Bioscience).

\section{ADCC Assay}

For experiments using the sera of mice immunized with OVA antigen, B16mOVA cells (target cells) were plated to 96-well U-bottom plates at $8 \times 10^{3}$ cells/well. B16F10 cells were used as a negative control. For experiments using the sera of mice immunized with influenza vaccine antigen, MDCK cells were infected with A/California/04/09 (pH1N1), A/Puerto Rico/8/34 $(\mathrm{H} 1 \mathrm{~N} 1$ ), or $\mathrm{H} 3 \mathrm{~N} 2$ (multiplicity of infection $=1$ ) in serumfree DMEM that contained $100 \mathrm{U} / \mathrm{ml}$ penicillin and $100 \mathrm{mg} / \mathrm{ml}$ streptomycin for $12 \mathrm{~h}$ at $37^{\circ} \mathrm{C}$. The virus-infected MDCK cells (target cells) were harvested and plated to 96-well U-bottom
A
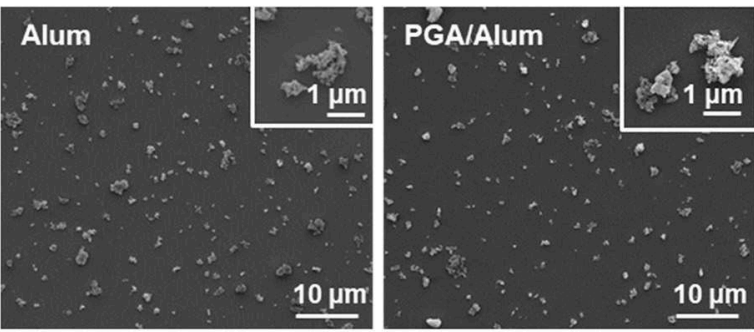

C

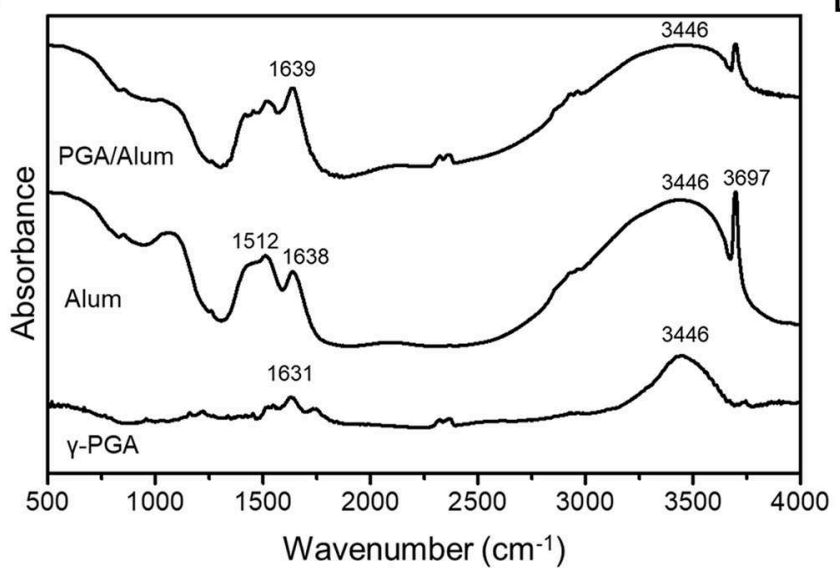

B

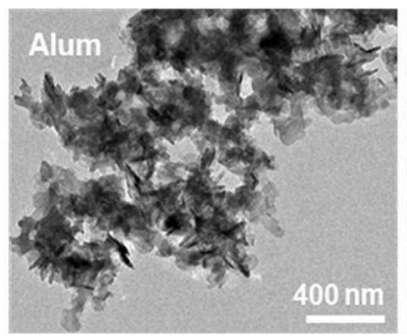

D

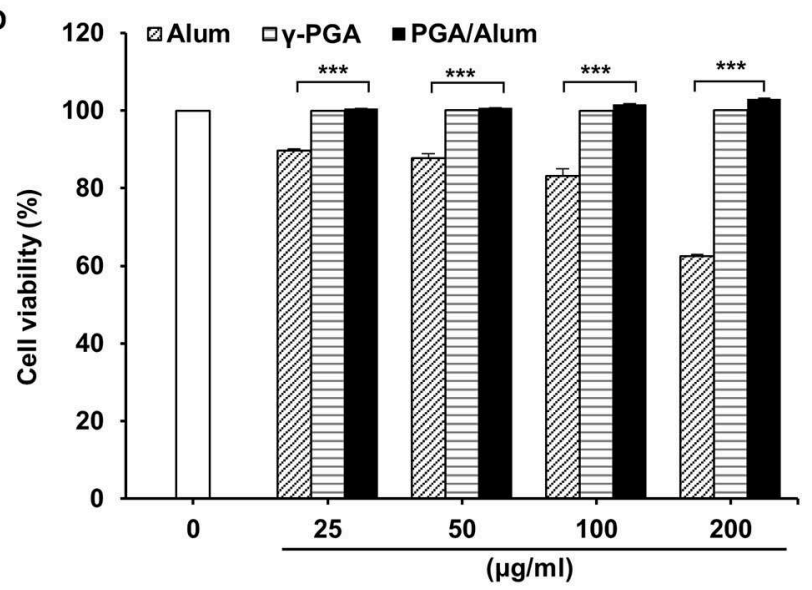

FIGURE 1 | The physiochemical characterization of PGA/Alum. (A) SEM and (B) TEM images of alum and PGA/lum (inset images are highly magnified). (C) FT-IR spectra of $\gamma$-PGA, alum, and PGA/Alum. (D) Cytotoxicity of PGA/Alum was evaluated by measuring cell viability of BMDCs exposed to various concentrations of alum, $\gamma$-PGA, and PGA/Alum for $24 \mathrm{~h}$. The data are representative of three independent experiments. Statistically significant differences were analyzed via ANOVA/Bonferroni. ${ }^{* \star \star} P<0.001$. 
TABLE 1 | Physiochemical characterization and OVA-loaded efficiencies of PGAVAlum.

\begin{tabular}{|c|c|c|c|c|}
\hline Sample & Particle size (diameter $\mathrm{nm} \pm \mathrm{SD}$ ) & Polydispersity index (PDI) & Zeta potential (mV) & OVA-loaded (mg/ml) \\
\hline Alum & $1,066.2 \pm 32.01$ & $0.31 \pm 0.03$ & $-7.08 \pm 0.91$ & $1.603 \pm 0.04$ \\
\hline PGA/Alum & $1,294.67 \pm 13.32$ & $0.37 \pm 0.03$ & $-28.10 \pm 1.49$ & $2.144 \pm 0.08$ \\
\hline
\end{tabular}

plates at $8 \times 10^{3}$ cells/well. The target cells were mixed with both heat-inactivated serum samples $\left(56^{\circ} \mathrm{C}, 1 \mathrm{~h}\right)$ and naïve $\mathrm{NK}$ cells and then incubated for $4 \mathrm{~h}$ at $37^{\circ} \mathrm{C}$. Cytotoxicity was assessed by detection of lactate dehydrogenase (LDH) in culture supernatants using a CytoTox 96 Non-radioactive cytotoxicity assay (Promega).

\section{Enzyme-Linked Immunospot (ELISPOT) Assay}

The frequencies of antigen-specific IFN- $\gamma$-producing cells were evaluated using a mouse ELISPOT kit (BD Bioscience), as previously described $(18,19)$. Briefly, splenocytes were obtained from immunized mice and plated at $5 \times 10^{5}$ cells/well onto purified anti-IFN- $\gamma$-coated ELISPOT plates. The cells were stimulated with $\mathrm{OVA}_{257-264}$ peptide $(0.5 \mu \mathrm{g} /$ well; Anaspec) or UV-inactivated viruses, including $500 \mathrm{TCID}_{50} /$ well of A/California/04/09 (pH1N1), 2,000 TCID $_{50} /$ well of A/Puerto Rico/8/34 (H1N1), or 2,000 $\mathrm{TCID}_{50} /$ well of $\mathrm{H} 3 \mathrm{~N} 2$ viruses for 3 days. The spot-forming units (SFUs) of IFN- $\gamma$-producing cells were counted using an ELISPOT plate reader (Cellular Technology Ltd).

\section{Hemagglutination-Inhibition (HI) Assay}

The serum HI titers against the A/California/04/09 (pH1N1) were determined as previously described (18). HI titers were recorded as the reciprocals of the highest serum dilution at which hemagglutination was prevented.

\section{Virus Titration in Lungs}

On days 3 and 7 post-challenge, mouse lung samples were homogenized in MEM that contained $0.2 \%$ BSA at $1 \mathrm{~g}$ of lung/ml. The homogenates were centrifuged at $15,000 \times g$ for $10 \mathrm{~min}$ at $4^{\circ} \mathrm{C}$ to remove cell debris, and the supernatants were used for the assay. The viral titers were calculated according to the method of Reed and Muench (20) and expressed as $\log _{10} \mathrm{TCID}_{50} / \mathrm{ml}$.

\section{Statistical Analysis}

Data are presented as the means \pm standard deviations (SDs) and represent at least three independent experiments. Significant differences between two groups were assessed using the twotailed Student's $t$-test, and differences among multiple groups were assessed using one-way ANOVA followed by Bonferroni's correction (ANOVA/Bonferroni). The log-rank test was used to analyze survival between two groups. $P$ values $<0.05$ were considered to be statistically significant. All analyses were performed using GraphPad PRISM software (GraphPad).

\section{RESULTS}

\section{PGA/Alum Complex Shows a High Antigen-Loading Capacity With No Cytotoxicity}

To develop a potential adjuvant for future clinical applications, we fabricated PGA/Alum by combining $\gamma$-PGA and alum, which is composed of aluminum hydroxide $(\mathrm{AH})$ and magnesium hydroxide $(\mathrm{MH})$. The size and morphology of the fabricated PGA/Alum were measured using dynamic light scattering, TEM, and SEM. Similar to alum, PGA/Alum exhibited an irregular morphology with an average diameter of 1-2 $\mu \mathrm{m}$ (Figures 1A,B), which is consistent with the morphology of alum in a previous report (21). As shown in Table 1, the hydrodynamic diameter of PGA/Alum $(1,294.67 \pm 13.32 \mathrm{~nm})$ was larger than that of alum $(1,066.2 \pm 32.01 \mathrm{~nm})$. The polydispersity index was $0.37 \pm 0.03$ for PGA/Alum and $0.31 \pm 0.03$ for alum, and was shown in the mid-range of the index value from 0.08 to 0.7 (22). The zetapotential value of alum was $-7.08 \pm 0.91 \mathrm{mV}$, while the value of the PGA/Alum complex was $-28.10 \pm 1.49 \mathrm{mV}$, which suggests that $\gamma$-PGA was successfully conjugated to alum. To confirm the chemical structures of $\gamma$-PGA, alum, and PGA/Alum, we used FT-IR analysis (Figure 1C). In the $\gamma$-PGA spectrum, a broad peak at $\sim 3,446 \mathrm{~cm}^{-1}$ was attributed to $\mathrm{N}-\mathrm{H}$ and $\mathrm{O}-\mathrm{H}$ stretching, while that at $1,631 \mathrm{~cm}^{-1}$ was attributed to the $\mathrm{C}=\mathrm{O}$ stretching of the carbonyl, as previously reported for $\gamma$-PGA (23). According to the manufacturer's description, the utilized alum is composed of $\mathrm{AH}$ and $\mathrm{MH}$ with inactive stabilizers. In the alum spectrum, the peaks at 3,697 and $3,446 \mathrm{~cm}^{-1}$ were attributed to the hydroxyl groups of $\mathrm{MH}$ and $\mathrm{AH}$, respectively, and those at 1,638 and $1,512 \mathrm{~cm}^{-1}$ were attributed to vibrations of the $\mathrm{Mg}-\mathrm{OH}$ and $\mathrm{OH}$ bonds, respectively, in the crystal structure (24-26). The spectrum of PGA/Alum showed distinct peaks that corresponded to alum and $\gamma$-PGA at 3,446 and $1,639 \mathrm{~cm}^{-1}$, respectively. Based on the results of the FT-IR analysis, we confirmed that $\gamma$-PGA and alum successfully formed a complex. We further examined the cytotoxicity of PGA/Alum using BMDCs exposed to alum, $\gamma$-PGA, or PGA/Alum for $24 \mathrm{~h}$. As shown in Figure 1D, the treatment of $\gamma$-PGA or PGA/Alum did not affect the cell viability, whereas alum dose-dependently decreased the cell viability as previously reported (21). Additionally, immunofluorescent microscopic analysis showed that PGA/Alum was efficiently taken up by BMDCs in vitro (Figure S1A). Production of IL-6 and IL- $1 \beta$ rapidly and transiently increased by PGA/Alum in the injection sites by $6 \mathrm{~h}$ post-injection but declined almost to basal levels by $24 \mathrm{~h}$ post-injection (Figure S1B). We further confirmed the safety of PGA/Alum by measuring body temperature and levels of inflammatory cytokines (IL-6 and TNF- $\alpha$ ) in the sera of the vaccinated mice at $6,24,48,72,96$, and $120 \mathrm{~h}$ 
post-vaccination. The PGA/Alum-vaccine group showed no significant change of body temperature compared with PBS or vaccine groups (Figure S2A). The level of serum IL-6 was higher in the PGA/Alum-vaccine and vaccine groups than PBS group at $6 \mathrm{~h}$ post-vaccination, but it maintained a basal level at $24 \mathrm{~h}$ postinjection. Serum TNF- $\alpha$ level was not changed in PGA/Alumvaccine, vaccine, and $\mathrm{PBS}$ groups (Figure S2B). These results support the safety of PGA/Alum after vaccination. To investigate the antigen encapsulation efficiency, we mixed PGA/Alum with OVA as a model protein antigen and used the BCA assay to measure the amount of loaded OVA. Our results indicated that PGA/Alum loaded significantly more OVA $(2.144 \pm 0.08 \mathrm{mg} / \mathrm{ml})$ than alum $(1.603 \pm 0.04 \mathrm{mg} / \mathrm{ml})$ (Table 1$)$. Taken together, our results indicate that the PGA/Alum complex successfully form under the utilized conditions and it shows a high antigen-loading capacity without cytotoxicity.

\section{PGA/Alum Significantly Enhances the Activation and Antigen Presentation of DCs in vitro}

Because DCs are professional antigen-presenting cells (APCs) that are responsible for the initiation of adaptive immunity (27), we examined the effect of PGA/Alum on DC activation. After immature BMDCs were prepared and stimulated with alum, $\gamma$ PGA, or PGA/Alum for $24 \mathrm{~h}$, the levels of pro-inflammatory cytokines and various costimulatory molecules were analyzed via ELISA and flow cytometry, respectively. As shown in Figure 2A, the mean fluorescence intensities (MFIs) of costimulatory molecules (CD40, CD80, and CD86) and MHC class II molecules were substantially increased on the PGA/Alum-exposed BMDCs compared to those treated with alum or $\gamma$-PGA. Similarly, PGA/Alum-treated BMDCs produced higher levels of cytokines (TNF- $\alpha$, IL-6, IL-1 $\beta$, and IL-12) than those stimulated with alum or $\gamma$-PGA alone $(P<0.01)$ (Figure 2B). To investigate the antigen uptake and degradation abilities of these cells, we incubated BMDCs with FITC-OVA or DQ-OVA, which is a self-quenching dye that emits green fluorescence upon the degradation of OVA. Flow cytometry showed that the MFIs of FITC-OVA or DQ-OVA were significantly higher in the PGA/Alum-treated BMDCs than in those treated with PBS, alum, or $\gamma$-PGA (Figure 2C), indicating that PGA/Alum substantially increases the antigen-uptake ability of DCs.

Because $\gamma$-PGA has been reported to activate DCs via TLR4 signaling (17), we prepared BMDCs from TLR4defective $\mathrm{C} 3 \mathrm{H} / \mathrm{HeJ}$ mice and used them to examine whether PGA/Alum-induced DC activation is mediated by TLR4. We observed a significantly lower level of TNF- $\alpha$ in BMDCs from TLR4-defective $\mathrm{C} 3 \mathrm{H} / \mathrm{HeJ}$ mice than from wild-type $\mathrm{C} 3 \mathrm{H} / \mathrm{HeN}$ mice following PGA/Alum treatment (Figure S3A). Furthermore, PGA/Alum induced little I $\mathrm{B} \alpha$ phosphorylation in TLR4-defective BMDCs, whereas the phosphorylation in wild-type BMDCs was dose-dependently increased by PGA/Alum (Figure S3B). Taken together, these results indicate that PGA/Alum activates DCs through NF- $\mathrm{B}$ signaling via TLR4.

\section{PGA/Alum Substantially Increases Antigen Trafficking and Migration of Antigen-Loaded DCs From Injection Sites to Draining Lymph Nodes}

The recruitment of DCs to the antigen injection site and the migration of antigen-loaded DCs to dLNs are vital steps in the induction of adaptive immunity and are important to the efficacy of a vaccine. Accordingly, we used Alexa Fluor 647-conjugated OVA (Fluor-OVA) to examine the effect of PGA/Alum on the recruitment of DCs and the migration of antigen-loaded DCs. Mice were i.m. injected with Fluor-OVA mixed with or without PGA/Alum, and flow cytometry was used to enumerate the DCs in injected muscle tissues and dLNs. Compared with the Fluor-OVA group, the number of DCs $\left(\mathrm{CD} 11 \mathrm{c}^{+} \mathrm{MHC}-\mathrm{II}^{+}\right)$was significantly increased in the muscle tissues of the PGA/Alum-Fluor-OVA group at 6 and $24 \mathrm{~h}$ postinjection (Figure 3A). Notably, we observed $\sim 2$-fold more DCs in the muscle tissues of the PGA/Alum-Fluor-OVA group (13.3 $\pm 2.2 \times 10^{3}$ cells/muscle) than in the Fluor-OVA group (5.5 $\pm 0.7 \times 10^{3}$ cells/muscle) at $24 \mathrm{~h}$ post-injection. Importantly, the number of antigen-loaded DCs (Fluor-OVA ${ }^{+} \mathrm{CD} 11 \mathrm{c}^{+} \mathrm{MHC}-$ $\mathrm{II}^{+}$) was increased in the dLNs of the PGA/Alum-Fluor-OVA group compared to the Fluor-OVA group, particularly at $6 \mathrm{~h}$ post-injection $\left(12.5 \pm 0.1 \times 10^{3}\right.$ cells/LN for the PGA/AlumFluor-OVA group and $7.1 \pm 2.5 \times 10^{3}$ cells/LN for the FluorOVA group) $(P<0.05)$ (Figure 3B). The fluorescent intensity of Fluor-OVA and the accumulation of $\mathrm{CD} 11 \mathrm{c}^{+} \mathrm{MHC}-\mathrm{II}^{+}$cells increased in both the injected muscle tissues and dLNs of the PGA/Alum-Fluor-OVA group at $6 \mathrm{~h}$ post-injection (Figure S4A). We also observed increased numbers of neutrophils and monocytes in the injected muscles of the PGA/Alum-FluorOVA group compared with the Fluor-OVA group at 3, 6, and $24 \mathrm{~h}$ post-injection (Figure S4B). Compared to other groups, the PGA/Alum-Fluor-OVA group had significantly higher DC numbers in injected muscle tissues and dLNs (Figure 3C) and higher antigen-loaded DCs numbers in dLNs (Figure 3D) at $24 \mathrm{~h}$ post-injection.

To assess the antigen delivery activity of PGA/Alum, we performed in vivo imaging of the antigen trafficking by PGA/Alum from the injection site to the dLNs using OVA with an NIR fluorescence imaging system. IRDye800-labeled OVA (OVA-IR800) alone or combined with alum, $\gamma$-PGA, or PGA/Alum were subcutaneously (s.c.) injected into the right forepaw pad of C57BL/6 mice, and in vivo fluorescent signals were observed at $1,3,6,24$, and $48 \mathrm{~h}$ post-injection. As shown in Figure 3E, the fluorescent intensities were significantly higher in the dLNs of the mice treated with PGA/Alummixed OVA-IR800 than in those of the mice exposed to OVAIR800 alone or mixed with alum or $\gamma$-PGA at 6,24 , and $48 \mathrm{~h}$ post-injection. Notably, the sustained fluorescent signal was observed in the dLNs of the PGA/Alum-mixed OVAIR800-treated mice until $48 \mathrm{~h}$ post-administration, but not in other groups, which implies that PGA/Alum acts as an efficient antigen carrier.

As chemokines modulate the migration of immune cells to dLNs (28-30), levels of various chemokines (MIP- $1 \alpha$, MIP- $1 \beta$, 


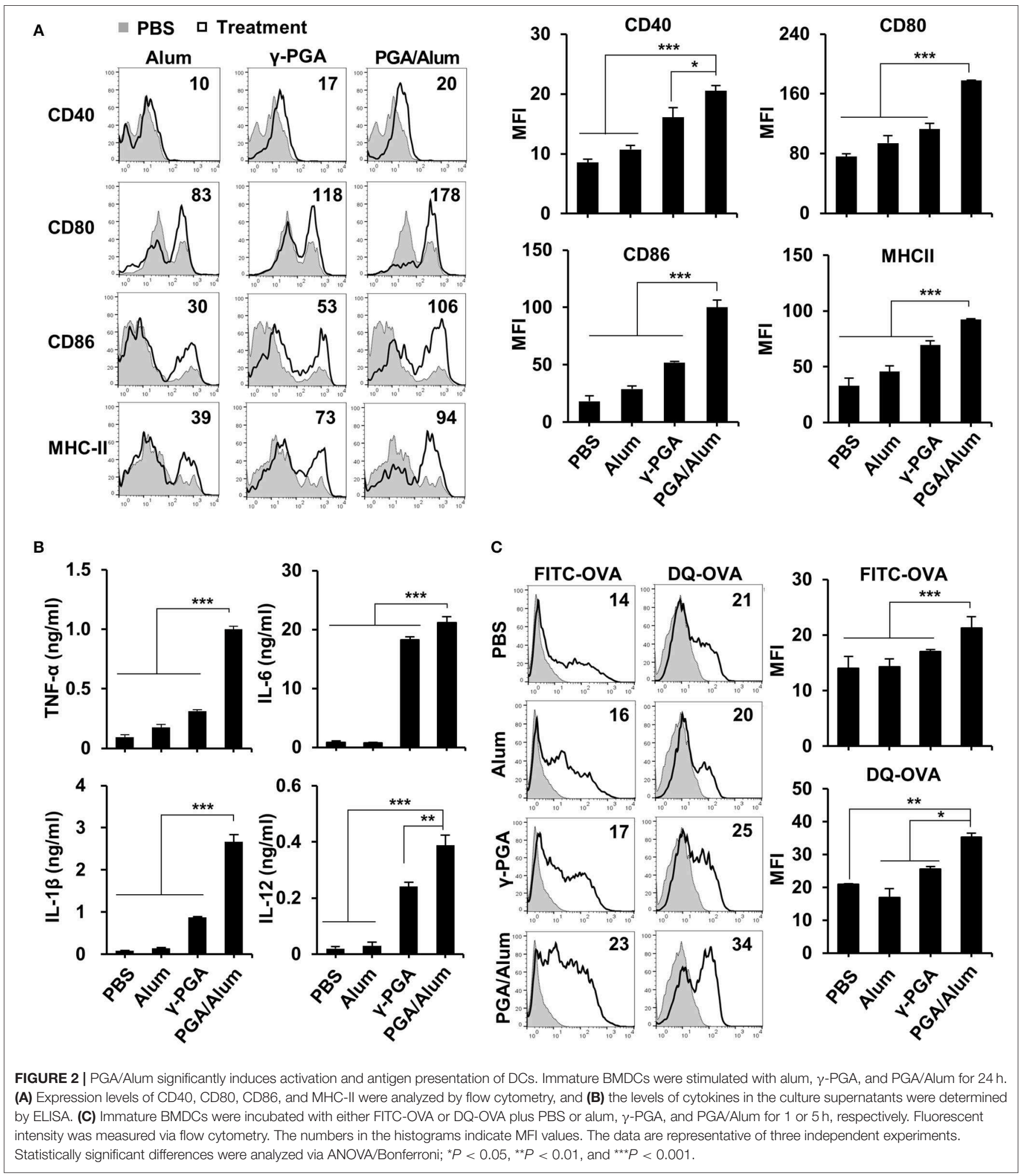

and MCP-1) were substantially enhanced in the homogenates from the muscle tissues of the PGA/Alum-OVA group, but not in those of the OVA group $(P<0.001)$ (Figure S5A). Increased chemokine levels were also observed in the dLN homogenates of the PGA/Alum-OVA group, but not in those of the OVA group. We additionally examined the expression of CCR7 responsible for migration of DCs from the antigen exposure site to dLNs (31). As expected, the expression of CCR7 was nearly 3 -fold higher on 
A

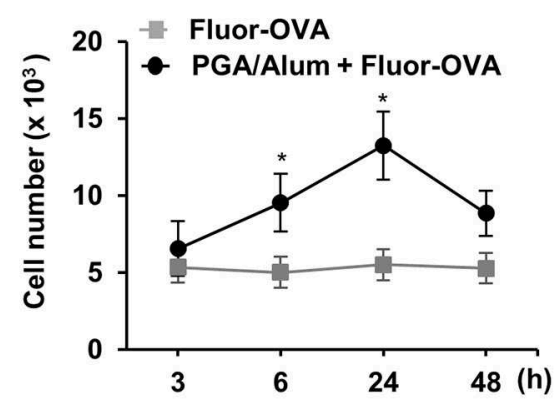

C

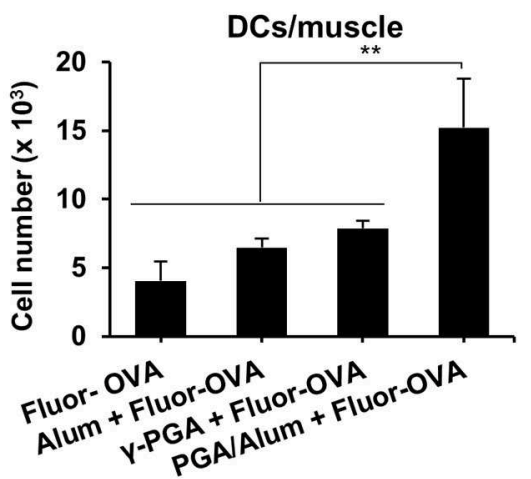

DCs/dLN

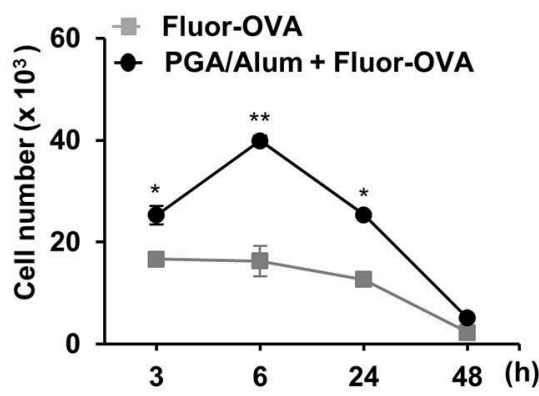

DCs/dLN

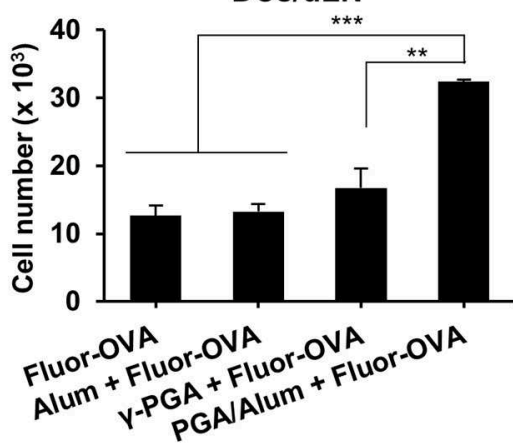

B

Fluor-OVA+ DCs/dLN

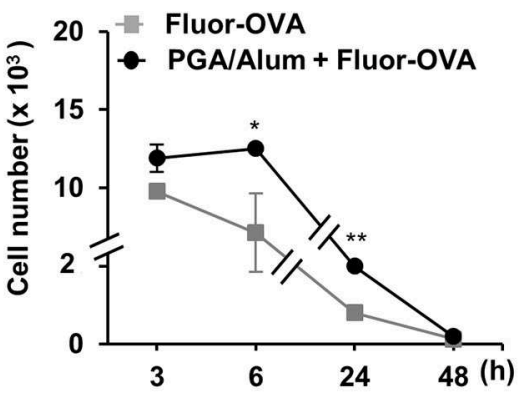

D

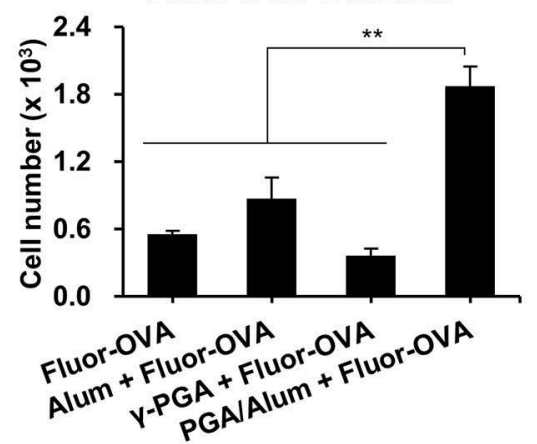

E
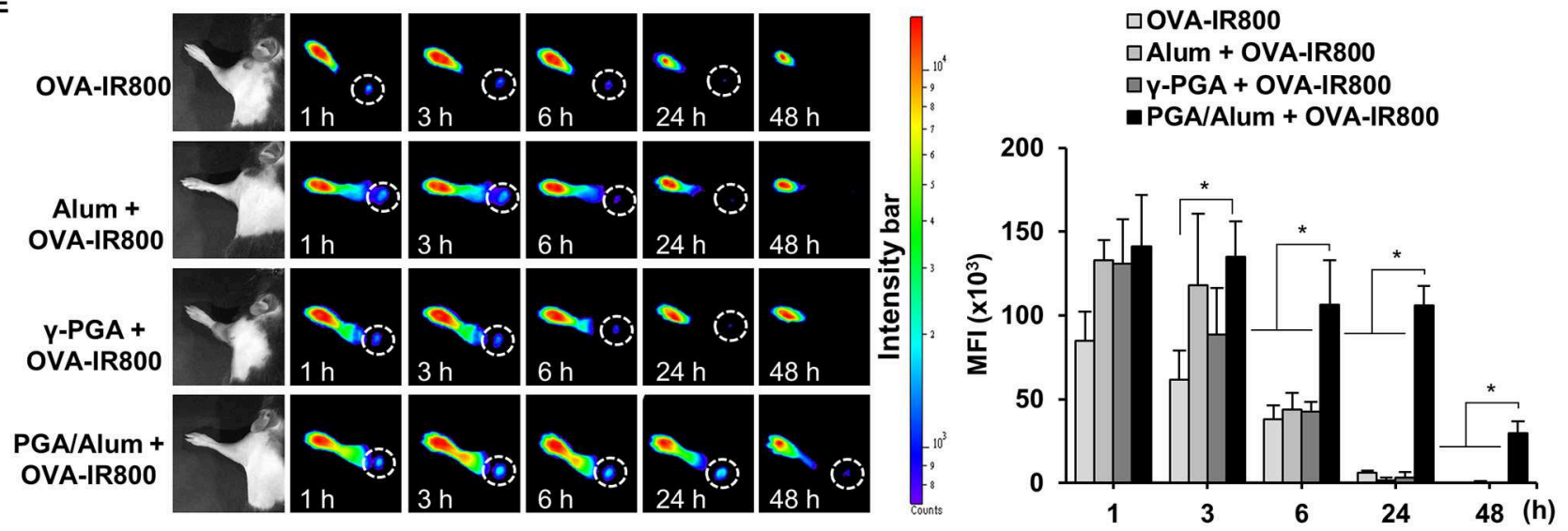

FIGURE 3 | PGA/Alum efficiently increases antigen trafficking from the injection site to dLNs. (A,B) C57BL/6 mice ( $n=3$ per group) were i.m. immunized with $5 \mu \mathrm{g}$ Fluor-OVA mixed with $800 \mu \mathrm{g}$ PGA/Alum. At 3, 6, 24, and $48 \mathrm{~h}$ post-immunization, the number of DCs (gated as CD11 ${ }^{+} \mathrm{MHC}^{-\|^{+}}$cells) per injected muscle and dLN (A) and Fluor-OVA-loaded DCs (gated as Fluor-OVA ${ }^{+}$CD $11 \mathrm{C}^{+} \mathrm{MHC}-\|^{+}$cells) per dLN (B) were analyzed via flow cytometry. (C,D) C57BL/6 mice $(n=3$ per group) were i.m. immunized with $5 \mu \mathrm{g}$ Alexa Fluor 647-conjugated OVA alone or combined with $400 \mu \mathrm{g}$ alum, $400 \mu \mathrm{g} \gamma$-PGA, or $800 \mu \mathrm{g}$ PGA/Alum. At $24 \mathrm{~h}$ post-immunization, the number of DCs per injected muscle and dLN (C) and Fluor-OVA-loaded DCs per dLN (D) were analyzed via flow cytometry. (E) Mice $(n=3$ per group) were s.c. injected into the right forepaw pad with $25 \mu \mathrm{g}$ OVA-IR800 alone or combined with $400 \mu \mathrm{g}$ alum, $400 \mu \mathrm{g} \gamma$-PGA, or $800 \mu \mathrm{g}$ PGA/Alum. At the indicated time points, in vivo NIR fluorescence signals were acquired using IVIS. Fluorescent intensities of each region of interest were quantitatively measured using ImageJ software (circle: axillary lymph node). The data are representative of three independent experiments. Statistically significant differences were identified via $t$-test; ${ }^{\star} P<0.05,{ }^{\star \star} P<0.01,{ }^{\star \star \star} P<0.001$. N.D, not-detected.

the PGA/Alum-exposed DCs than on those exposed to alum or $\gamma$-PGA (Figure S5B). Also, the mice administered PGA/Alummixed Fluor-OVA had significantly higher expression of CCR7 on the DCs in the dLNs than other groups (Figure S5C).
Collectively, these results indicate that PGA/Alum enhances the recruitment of DCs to injection sites and the migration of antigen-loaded DCs to dLNs through increases of chemokine production and CCR7 expression. 


\section{PGA/Alum Enhances OVA-Specific Humoral and Cellular Immune Responses}

To evaluate the effect of PGA/Alum on antigen-specific humoral and cellular immunity, we i.m. injected mice with OVA mixed with alum (alum-OVA), $\gamma$-PGA ( $\gamma$-PGA-OVA), or PGA/Alum (PGA/Alum-OVA) on days 0,14 , and 28. Two weeks after the last immunization, ELISA was employed to measure the levels of OVA-specific Abs in the sera of the immunized mice. Our results showed that the levels of IgG, IgG1, and IgG2b significantly increased in the sera of the PGA/AlumOVA group compared with those of the OVA, alum-OVA, and $\gamma$-PGA-OVA groups $(P<0.001)$ (Figure 4A; Figure $S 6$ ). This finding indicates that PGA/Alum increases antigen-specific humoral immunity.

We subsequently examined the ADCC of natural killer (NK) cells, which is crucial for eliminating Ab-bound target cells (e.g., virus-infected cells) $(32,33)$. To investigate the effect of PGA/Alum on the ADCC activity of NK cells, we examined the CD107a expression and the IFN- $\gamma$ production of NK cells, as well as target cell cytolysis using B16mOVA cells (OVAexpressed B16F10 cells). The activation of NK cells was robustly enhanced by co-culture with a mixture of B16mOVA cells and the sera of the PGA/Alum-OVA group $(5.5 \pm 1.2 \%$ for IFN- $\gamma^{+} \mathrm{CD} 107 \mathrm{a}^{+}$and $39.6 \pm 4.6 \%$ for $\left.\mathrm{CD} 107 \mathrm{a}^{+}\right)$compared with the OVA $\left(1.2 \pm 0.1 \%\right.$ for IFN $-\gamma^{+} \mathrm{CD} 107 \mathrm{a}^{+}$and 25.9 $\pm 1.6 \%$ for $\left.\mathrm{CD}_{107 \mathrm{a}^{+}}\right), \gamma$-PGA-OVA $(1.2 \pm 0.3 \%$ for IFN$\gamma^{+} \mathrm{CD}_{107 \mathrm{a}^{+}}$and $25.8 \pm 2.4 \%$ for $\left.\mathrm{CD} 107 \mathrm{a}^{+}\right)$, and alumOVA $\left(2.1 \pm 0.1 \%\right.$ for IFN- $\gamma^{+}$CD107a ${ }^{+}$and $27.3 \pm 1.9 \%$ for

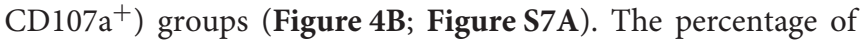
cytotoxicity was also higher in the PGA/Alum-OVA group (60 $\pm 5 \%)$ than in the $\gamma$-PGA-OVA $(50 \pm 4 \%)$, alum-OVA (50 $\pm 8 \%$ ), or OVA $(41 \pm 3 \%)$ groups (Figure S7B). In addition, we investigated whether PGA/Alum enhances cellular immune responses specific to $\mathrm{OVA}_{257-264}$ peptides which are $\mathrm{MHC}$ class I-restricted peptide epitope of OVA. ELISPOT assay revealed that the number of $\mathrm{OVA}_{257-264}$-specific IFN- $\gamma$-secreting cells was significantly higher in the PGA/Alum-OVA group than in the OVA or alum-OVA groups $(P<0.01)$ (Figure 4C). Moreover, flow cytometry showed that the frequency of $\mathrm{OVA}_{257-264}$ tetramer-positive $\mathrm{CD}^{+} \mathrm{T}$ cells was significantly increased in PGA/Alum-OVA compared to other groups $(P<0.01)$ (Figure 4D). These findings indicate that PGA/Alum enhances antigen-specific cellular immune responses, such as ADCC and CTL activities.

As immunological memory is a critical goal for effective vaccination, we examined the long-term immunity of mice treated with OVA, alum-OVA, $\gamma$-PGA-OVA, or PGA/AlumOVA. As shown in Figure 4E, on day 180 after the final immunization, the PGA/Alum-OVA group showed a significantly higher IgG level than the other groups $(P<0.01)$. Notably, the increased IgG level of the PGA/Alum-OVA group was similar on days 14 and 180 after the final immunization, whereas those of the alum-OVA and $\gamma$-PGA-OVA groups had decreased to the baseline level by day 180 after the final immunization. The frequency of $\mathrm{OVA}_{257-264}$-specific IFN- $\gamma$ secreting cells was also higher in the PGA/Alum-OVA group than in the groups treated with OVA or alum-OVA $(P<0.01)$
(Figure 4F). The PGA/Alum-OVA group also exhibited higher IgG1 and IgG2b levels (Figure S8A), greater percentages of both plasma cells and memory B cells (Figure S8B), more ADCC activity (Figure S8C), and a higher frequency of $\mathrm{OVA}_{323-339}$ peptide-specific IL-4-secreting cells (Figure S8D) on day 180 after the final immunization. Taken together, these results demonstrate that PGA/Alum could be a potential adjuvant capable of enhancing humoral and cellular immunity and inducing persistent long-term immunity.

\section{PGA/Alum Substantially Enhances the Protective Efficacy of Influenza Vaccine Antigen}

To evaluate whether PGA/Alum improves the protective efficacy of a vaccine antigen, we investigated the effect of PGA/Alum on the immunogenicity and efficacy of $\mathrm{pH} 1 \mathrm{~N} 1$ split vaccine antigen. Mice were i.m. immunized with the $\mathrm{pH} 1 \mathrm{~N} 1$ split vaccine antigen (A/California/7/2009 NYMC X-179A H1N1) mixed with PGA/Alum (PGA/Alum-vaccine), alum (alum-vaccine), or $\gamma$-PGA $(\gamma$-PGA-vaccine) on days 0 and 14 . The mice immunized with vaccine antigen alone or PBS were used as negative controls. Fourteen days after the final immunization, the immunized mice were intranasally (i.n.) challenged with a lethal dose $\left(50 \mathrm{LD}_{50}\right)$ of $\mathrm{pH} 1 \mathrm{N1}$ virus (A/California/04/09). As shown in Figures 5A,B, the mice of the PGA/Alum-vaccine group showed $100 \%$ survival without considerable body weight loss for 14 days after this viral challenge. In contrast, the mice immunized with alum-vaccine and $\gamma$-PGA-vaccine showed severe body weight loss and were only partially protected, exhibiting survival rates of 16.7 and $33.3 \%$, respectively. The mice immunized with PBS or vaccine alone had $0 \%$ survival. As viral clearance from the infected lung is a crucial indicator of the protective efficacy of a vaccine, we determined viral titers in lung homogenates on days 3 and 7 post-infection. As expected, the PGA/Alum-vaccine group exhibited viral clearance on day 7 post-challenge, whereas the other groups continued to exhibit high viral titers at this point (Figure 5C). Our findings indicate that PGA/Alum substantially enhances the protection efficacy of the pH1N1 split vaccine antigen against $\mathrm{pH} 1 \mathrm{~N} 1$ virus challenge.

To confirm the adjuvant effect of PGA/Alum for the influenza vaccine, we examined IgG titers, hemagglutination-inhibition (HI) titers, ADCC, and CTL activities. As shown in Figure 5D, the titers of influenza antigen-specific IgG, IgG1, and IgG2b were higher in the sera obtained from the mice of the PGA/Alumvaccine group than those obtained from the other groups. The HI titers were also substantially increased in the sera of the mice from the PGA/Alum-vaccine group (359 \pm 180 geometric mean titer [GMT]) compared to those of the other groups (90 \pm 45 GMT for alum-vaccine, $9 \pm 6$ GMT for $\gamma$-PGA-vaccine, $20 \pm 14$ GMT for vaccine, and $1 \pm$ GMT for PBS) (Figure 5E), which indicates that PGA/Alum confers neutralizing humoral immunity. Next, when ADCC activity was analyzed by measuring lysis of pH1N1-infected MDCK cells through co-culture of NK cells and the sera Abs of immunized mice, the sera Abs of PGA/Alum-vaccine group had significantly higher ADCC 
A

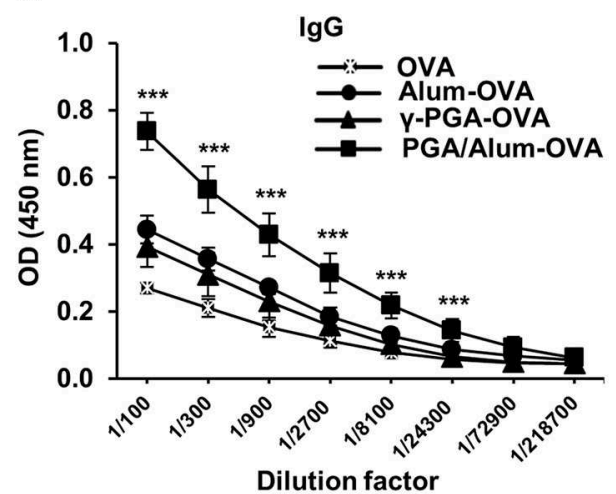

C

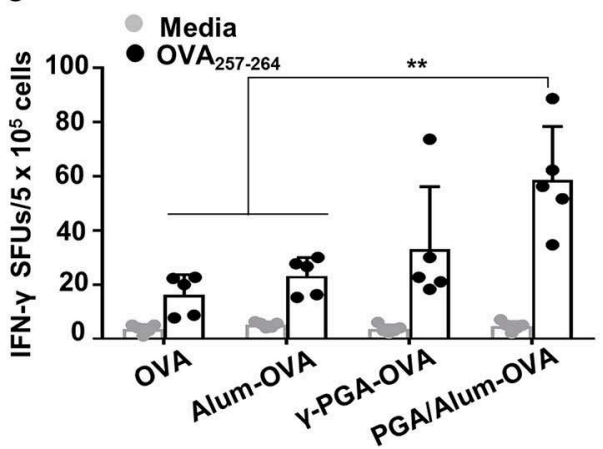

E

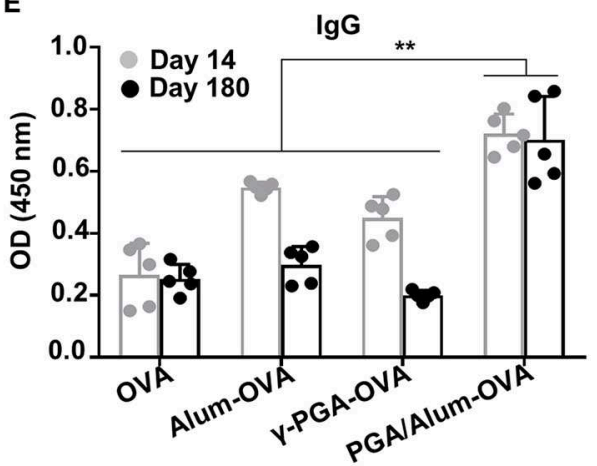

B

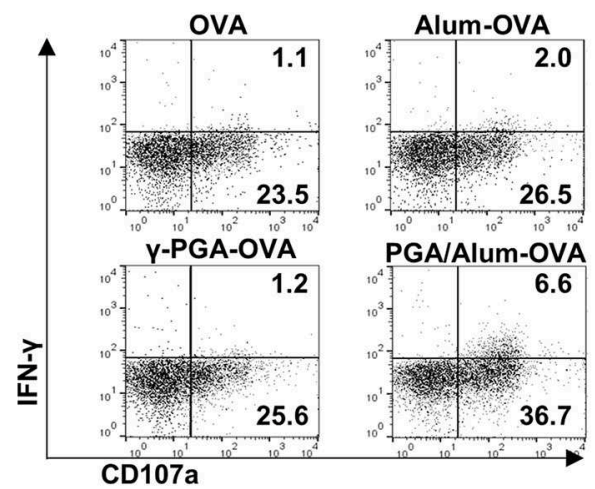

D

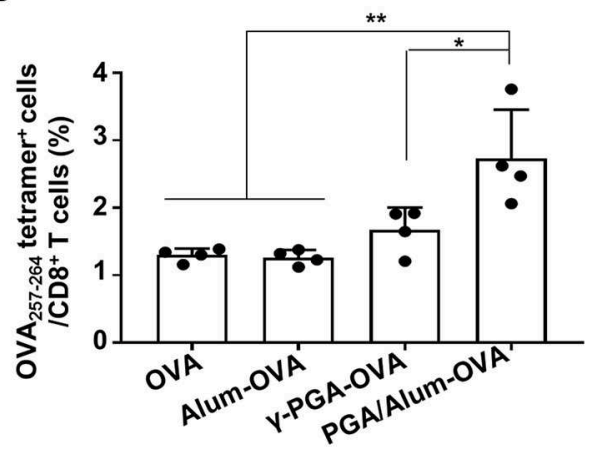

$\mathbf{F}$

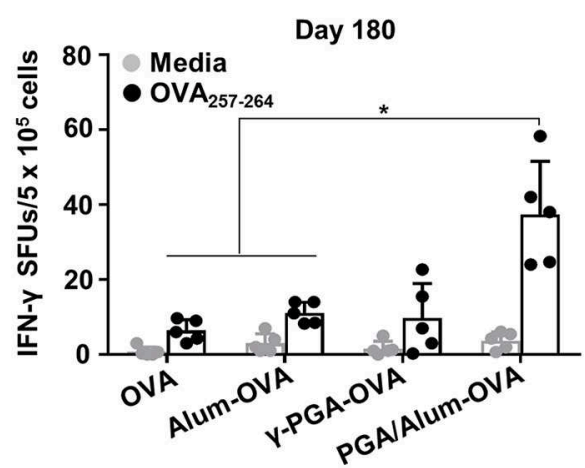

FIGURE 4 | PGA/Alum enhances OVA-specific humoral and cellular immune responses. C57BL/6 mice ( $n=5$ per group) were i.m. immunized with $10 \mu \mathrm{g}$ OVA protein combined with $400 \mu \mathrm{g}$ alum, $400 \mu \mathrm{g} \gamma$-PGA, or $800 \mu \mathrm{g}$ PGA/Alum on days 0,14 , and 28 . Fourteen (A-D) and 180 (E,F) days after the last immunization, sera and splenocytes were obtained from the immunized mice. (A) Serum levels of OVA-specific IgG were measured via ELISA. (B) OVA-coated plates were incubated with heat-inactivated serum samples $\left(1 \mathrm{~h}\right.$ at $\left.56^{\circ} \mathrm{C}\right)$, washed, and then further incubated for $5 \mathrm{~h}$ with naive $\mathrm{NK}$ cells in the presence of PE-conjugated anti-CD107a Ab, monensin, and brefeldin A. The cells were fixed, permeabilized, and stained with APC-conjugated anti-IFN- $\gamma$ Ab. Activation of NK cells was assessed by flow cytometry. (C) Splenocytes were stimulated with OVA $257-264$ peptide for 3 days, and the number of OVA $257-264$-specific IFN- $\gamma$ spot forming units (SFUs) was determined by an ELISPOT assay. (D) Frequency of $\mathrm{OVA}_{257-264}$ tetramer ${ }^{+} \mathrm{CD}^{+} \mathrm{T}$ cells was determined in the splenocytes using flow cytometry. (E) The level of OVA-specific IgG at days 14 and 180 post-immunization and (F) the number of OVA $257-264$-specific IFN- $\gamma$ SFUs on day 180 were determined by ELISA and an ELISPOT assay, respectively. Data are representative of three independent experiments with similar results. Statistically significant differences were identified via ANOVA/Bonferroni; ${ }^{\star} P<0.05,{ }^{\star \star} P<0.01$, and ${ }^{\star \star *} P<0.001$.

activities $(58.2 \pm 0.5 \%)$ compared with those of the other groups $(18.5 \pm 0.2 \%$ for alum-vaccine, $32.8 \pm 3.6 \%$ for $\gamma$ PGA-vaccine, $14.7 \pm 3.5 \%$ for vaccine, and $8.2 \pm 3.1 \%$ for PBS) (Figure 5F). Moreover, ELISPOT assay showed that the mice of the PGA/Alum-vaccine group yielded significantly more $\mathrm{pH} 1 \mathrm{~N} 1$ virus-specific IFN- $\gamma$-secreting cells than the other groups
$(P<0.05)$ (Figure 5G). The percentages of IFN- $\gamma$-secreting $\mathrm{CD}^{+}$and $\mathrm{CD}^{+} \mathrm{T}$ cells were also higher in the PGA/Alum group than in the other groups (Figure S9). Taken together, our results suggest that PGA/Alum enhances the protective efficacy of the influenza vaccine antigen by modulating influenza antigenspecific humoral and cellular immunity. 


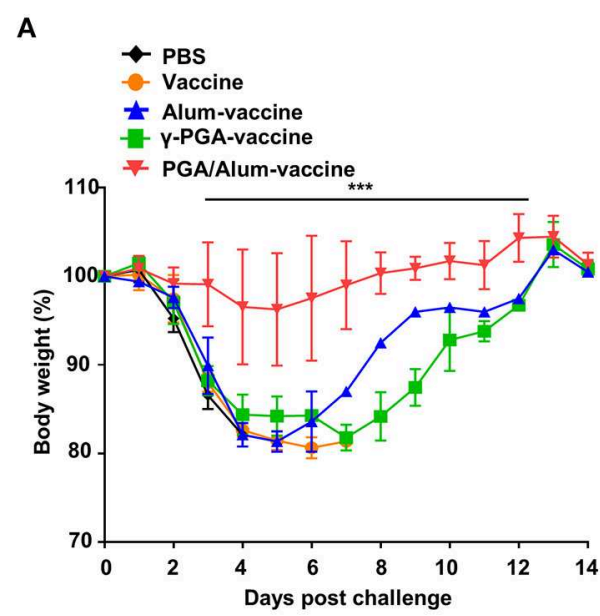

D

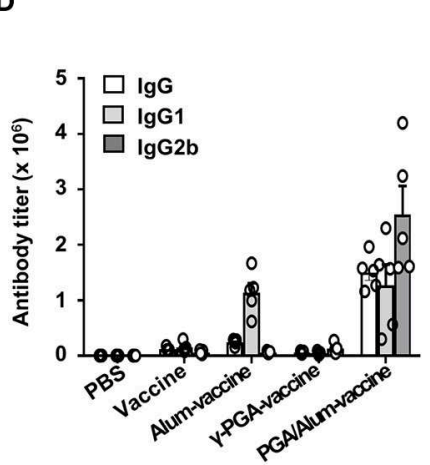

E

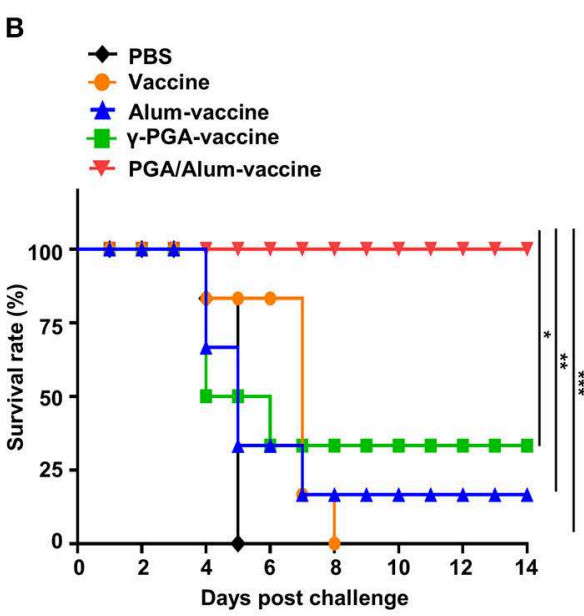

C

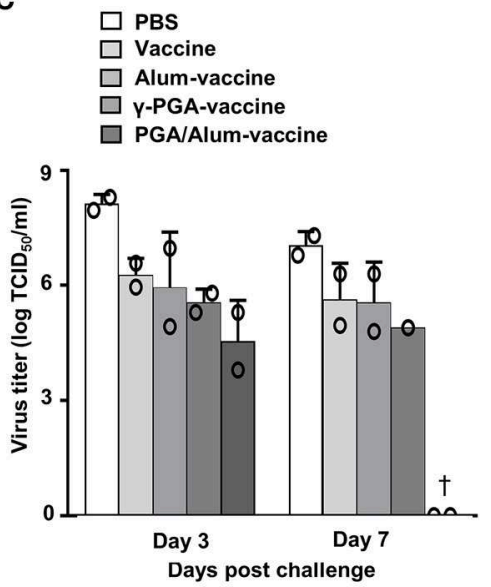

$\mathbf{F}$
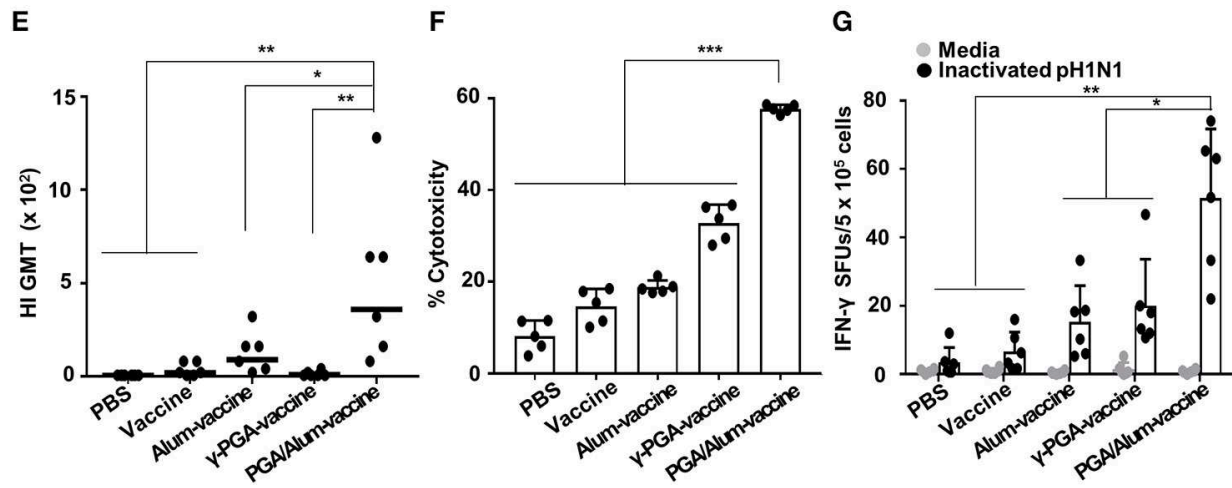

FIGURE 5 | PGAVAlum improves the protective efficacy of influenza vaccine antigen. C57BL/6 mice ( $n=6$ per group) were i.m. immunized with the $0.05 \mu \mathrm{g}$ pH1N1 split vaccine antigen combined with $400 \mu \mathrm{g}$ alum, $400 \mu \mathrm{g} \gamma$-PGA, or $800 \mu \mathrm{g}$ PGAVAlum on days 0 and 14 . Two weeks after the final administration, the mice were i.n. challenged with $50 \mathrm{LD}_{50} \mathrm{pH} 1 \mathrm{~N} 1$ virus. (A) Body weight changes and (B) survival rates were monitored for up to 14 days post-infection (dpi). Each data point represents an average percentage. Statistically significant differences were identified via the log-rank test. (C) Lung homogenates of each group were obtained at 3

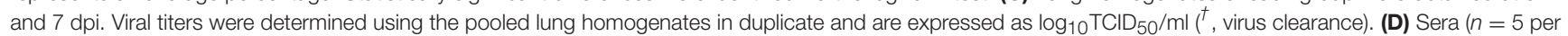
group) were collected before the viral challenge, and endpoint titers of vaccine-specific Abs are expressed as the mean $\pm \mathrm{SD}$. (E) Serum $\mathrm{HI}$ titers against a pH1N1 virus were measured. The lines indicate geometric means, and negative titers were assigned a value of 5 for calculation. (F) The pH1N1-infected MDCK cells were incubated with naïve NK cells in the presence of the sera from immunized mice, and cytotoxicity was assessed by LDH assay. (G) The number of influenza virus antigen-specific IFN- $\gamma$-secreting splenocytes was determined via ELISPOT assays. Data are representative of at least three independent experiments. Statistically significant differences were identified by ANOVA/Bonferroni; ${ }^{*} P<0.05,{ }^{\star *} P<0.01$, and ${ }^{\star * *} P<0.001$.

\section{PGA/Alum Substantially Improves the Cross-Reactive Immunity of Influenza Vaccine Antigen}

Given our observations that PGA/Alum increased the ADCC and CTL activities responsible for cross-reactivity against heterologous influenza virus, we speculated that PGA/Alum might enhance the cross-protective efficacy of $\mathrm{pH} 1 \mathrm{~N} 1$ vaccine antigen. To evaluate the impact of PGA/Alum on this crossreactivity, mice were immunized the $\mathrm{pH} 1 \mathrm{~N} 1$ split vaccine antigen mixed with alum, $\gamma$-PGA, or PGA/Alum and then challenged with A/Puerto Rico/8/34 (H1N1). Body weight decreased similarly across all groups until 6 days after the viral challenge, but was recovered faster by the PGA/Alum-vaccine group compared to the other groups (Figure 6A). Importantly, all mice of the PGA/Alum-vaccine group showed $100 \%$ survival, whereas only partial survival (40\%) was observed in the alum-vaccine and $\gamma$-PGA-vaccine groups (Figure 6B). To ascertain the effect of PGA/Alum on cross-protective immunity, we challenged the vaccinated mice with heterosubtypic influenza A virus, H3N2. Mice of the PGA/Alum-vaccine group efficiently recovered the body weight lost following viral challenge and showed $80 \%$ survival. In contrast, only $20 \%$ of mice in the alum-vaccine or $\gamma$-PGA-vaccine groups survived, and no survival was seen in the $\mathrm{PBS}$ or vaccine-alone groups (Figures 6C,D).

To better understand the mechanisms underlying PGA/Alum-enhanced cross-reactive protection, we examined cross-reactive ADCC and CTL activities. Our ADCC assay revealed that the cytolysis of heterologous influenza virus (H1N1 or H3N2)-infected MDCK cells was significantly increased by co-culture with naive NK cells and serum Abs obtained from the PGA/Alum-vaccine group $(25.6 \pm 1.9 \%$ for H1N1infected MDCK cells and $31.1 \pm 1.3 \%$ for $\mathrm{H} 3 \mathrm{~N} 2$-infected 
A

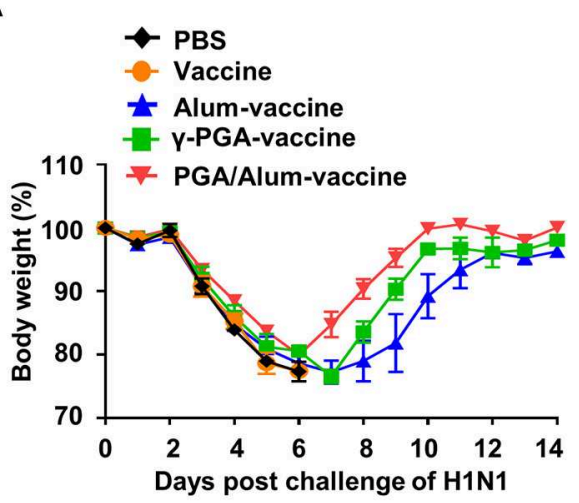

C

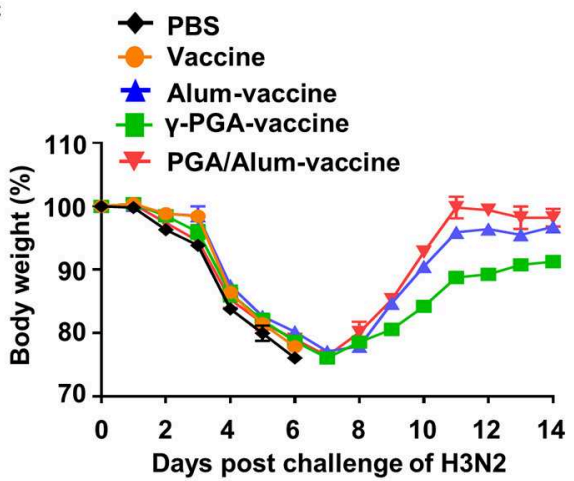

$\mathbf{E}$

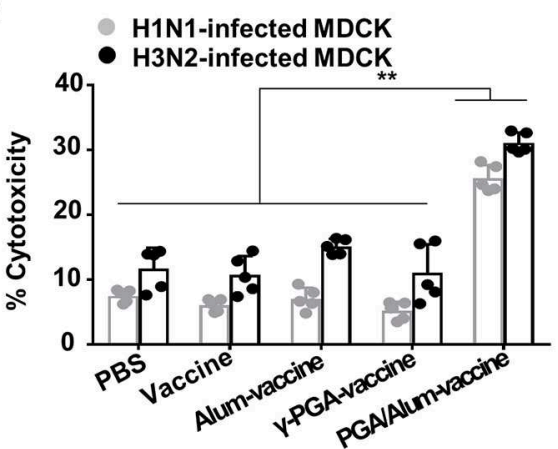

B

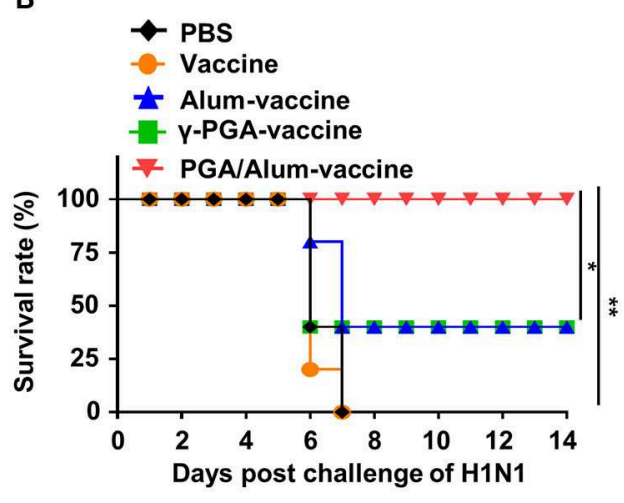

D
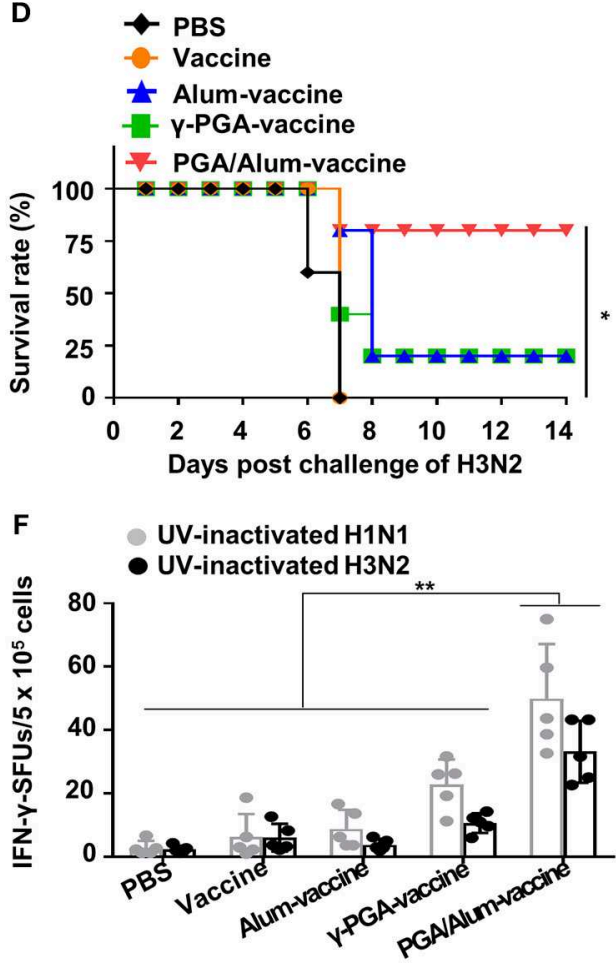

FIGURE 6 | PGA/Alum enhances cross-protective efficacy of $\mathrm{pH} 1 \mathrm{~N} 1$ vaccine antigen. C57BL/6 mice ( $n=5$ per group) were vaccinated i.m. with $0.5 \mu \mathrm{g}$ the $\mathrm{pH} 1 \mathrm{~N} 1$ split vaccine antigen together with $400 \mu \mathrm{g}$ alum, $400 \mu \mathrm{g} \gamma$-PGA, or $800 \mu \mathrm{g}$ PGA/Alum on days 0 and 14. Two week after the last immunization, the mice were i.n. challenged with $10 \mathrm{LD}_{50} \mathrm{H} 1 \mathrm{~N} 1$ virus (A/Puerto Rico/8/1934) (A,B) or $10 \mathrm{LD}_{50} \mathrm{H} 3 \mathrm{~N} 2$ viruses (C,D). Body weight and survival rates were monitored for 14 days. (E,F) Before viral challenge, sera and splenocytes were harvested from the immunized mice. (E) ADCC activity was determined by measuring lysis of H1N1- or H3N2-infected MDCK cells by co-culture of sera from the vaccinated mice and naiive NK cells. (F) Splenocytes were stimulated with UV-inactivated H1N1 or UV-inactivated H3N2 for 3 days, and the number of IFN- $\gamma^{+}$SFUs was determined by an ELISPOT assay. Statistically significant differences were identified by one-way ANOVA/Bonferroni or log-rank test (for survival); ${ }^{*} P<0.05$ and ${ }^{* *} P<0.01$.

MDCK cells), but not serum Abs obtained from mice exposed to alum-vaccine $(6.9 \pm 1.3 \%$ and $15.1 \pm 1 \%$, respectively), $\gamma$-PGA-vaccine $(5.2 \pm 1.2$ and $11.1 \pm 3.5 \%$, respectively), vaccine alone $(6.0 \pm 0.8$ and $10.7 \pm 2.9 \%$, respectively), or PBS (7.5 \pm 0.9 and $11.8 \pm 2.9 \%$, respectively) (Figure 6E). To clearly elucidate Ab-mediated contribution of PGA/Alumenhanced heterosubtypic cross-protection, we further performed in vivo protection assay as previously described $(34,35)$. Heat-inactivated sera from the immunized mice were mixed with $\mathrm{H} 3 \mathrm{~N} 2$ virus, and then the mixture was i.n. challenged to Balb/c mice. As shown in Figure S10, at day 14 post-infection, mice exposed to the mixture of $\mathrm{H} 3 \mathrm{~N} 2$ virus and PGA/Alumvaccine-immunized sera had $20 \%$ survival rate, whereas all mice of other groups died ( $0 \%$ survival rate), indicating that PGA/Alum-enhanced $\mathrm{Ab}$ production may partially contribute to heterosubtypic cross-protection. As the ADCC-mediating Abs are thought to recognize the highly conserved stalk domain of hemagglutinin (HA) on the influenza virus, thereby leading 
to cross-protection (36), we tested ADCC-mediated NK cell activation by incubating the serum Abs with the HA stalk protein. Our results revealed that HA stalk protein-preincubated serum Abs from the PGA/Alum-vaccine group significantly increased the percentages of IFN- $\gamma^{+} \mathrm{NK}$ and $\mathrm{CD} 107^{+} \mathrm{IFN}-\gamma^{+}$ NK cells (Figure S11), indicating that the PGA/Alum-induced Abs effectively bind to the HA stalk domain and subsequently activate NK cells. Additionally, we performed ELISAs to measure antibodies against the HA stalk using a recombinant HA stalk protein from A/Puerto Rico/8/1934 (H1N1) which share 94\% identity to A/California/04/09 (pH1N1) and 50\% identity to A/Hong Kong/1/68 (H3N2) virus. HA stalk-specific IgG level was significantly higher in the sera from the PGA/Alum-vaccine group than those in other groups, although the $\mathrm{pH} 1 \mathrm{~N} 1$ vaccine alone group very little elicited H1 HA stalk-specific IgG level (Figure S12A). We further tested H3 ELISA using a recombinant $\mathrm{HA} 1$ protein of $\mathrm{H} 3 \mathrm{~N} 2$ virus to investigate whether cross-reactive neutralizing Abs contribute to cross-protection against H3N2 virus. None of the $\mathrm{pH} 1 \mathrm{~N} 1$ vaccine antigen-immunized groups elicited H3 HA1-specific IgG titers (Figure S12B). Moreover, the sera Abs from all groups had no cross HI reactivity against heterosubtypic $\mathrm{H} 3$ virus (Figure $\mathrm{S12C}$ ). These results suggest that PGA/Alum elicits HA stalk Abs but not cross-reactive neutralizing Abs. Furthermore, an ELISPOT assay revealed that PGA/Alum increased cross-reactive CTL activity. As shown in Figure 6F, the number of $\mathrm{H} 1 \mathrm{~N} 1$-specific IFN- $\gamma$-secreting splenocytes was at least 2-fold higher in the PGA/Alum-vaccine group (50 \pm 17 SFUs) compared to the other groups ( $23 \pm 8$ SFUs for $\gamma$-PGA-vaccine, $9 \pm 6$ SFUs for alum-vaccine, $6 \pm 7$ SFUs for vaccine alone, and $3 \pm 2$ SFUs for PBS). Moreover, the number of H3N2-specific IFN- $\gamma$-secreting cells was at least 3 -fold higher in the PGA/Alum-vaccine group ( $33 \pm 10$ SFUs) than in the other groups $(11 \pm 3$ SFUs for $\gamma$-PGA-vaccine, 4 \pm 2 SFUs for alum-vaccine, $6 \pm 4$ SFUs for vaccine alone, and $2 \pm 1$ SFUs for PBS $)(P<0.01)$. Collectively, these findings demonstrate that PGA/Alum could enhance cross-protection by improving cross-reactive ADCC and CTL activities.

\section{DISCUSSION}

Currently, researchers are seeking to develop new adjuvants that increase vaccine-induced protection against infectious diseases. The use of TLR agonists as vaccine adjuvants is considered a promising means to improve vaccine efficacy, because TLR4 activates innate immune responses and subsequently augments adaptive immune responses by enhancing Th1-biased responses $(14,15)$. The combination of a TLR4 agonist with a Th2 adjuvant (e.g., alum) could be a beneficial strategy for tailoring immune responses through synergistic effects. The value of this strategy was emphasized by the recent approval for human use of AS04, which comprises MPL (a TLR4 agonist) absorbed on alum $(37,38)$. However, the purification of MPL requires extensive chemical modification of biologically derived LPS. There is a large batch-to-batch variability, the cost is prohibitive, and there are safety concerns. To address these limitations, we set out to replace MPL with the safe and cost-effective biomaterial,
$\gamma$-PGA, to generate the new combination of PGA/Alum and demonstrated its efficacy as an adjuvant, as summarized in Figure 7. We propose that the synergistic effect of PGA/Alum is mediated mainly by $\gamma$-PGA-induced innate immune activity plus alum-induced depot effect. $\gamma$-PGA activates innate immune responses including increases of costimulatory molecule expression and cytokine production of APCs. Concomitantly, alum induces vaccine antigen depots capable of enhancing antigen presentation by activating APCs. Also, antigen loading capacity of PGA/Alum may be enhanced by biopolymeric property of $\gamma$-PGA and antigen absorption capacity of alum. The combined effect of $\gamma$-PGA and alum could robustly provoke Th1 immune responses to enhance CTL activity and highly increase humoral immune responses, thereby leading to improved vaccine efficacy.

An ideal vaccine adjuvant should have a broad-spectrum of safety. We observed that PGA/Alum had very little cytotoxic effect on cells in vitro, although alum itself induced cytotoxicity. We speculate that the combination of $\gamma$-PGA with alum may be able to block the cytotoxicity of alum. It has been reported that immunization of MF59-adjuvanted influenza vaccine induced adverse reaction (e.g., redness and swelling at the injection site) compared to unadjuvanted vaccine in children $(39,40)$. By visual observation, administration of PGA/Alum induced no redness and swelling at the injection site (data not shown). Especially, no significant changes of body temperature as well as inflammatory cytokines were observed in the sera of the vaccinated mice. These findings suggest that PGA/Alum may be safe to use. In addition, $\gamma$-PGA can be produced on an industrial scale without complex requirements, and thus does not have the limitations associated with the complicated process required to manufacture MPL. A side-by-side comparison of adjuvants including MF59 and AS04 is important to elucidate the adjuvant effect of PGA/Alum. Unfortunately, we cannot compare the adjuvant effect of AS04 and PGA/Alum, because AS04 is unavailable for research use. In the case of MF59, we made squalene-based oil-in-water nano-emulsion with a formulation similar to MF59 (MF59-like adjuvant). In influenza vaccine experiments, PC nanogel $[\gamma$-PGA/chitosan nanogel adjuvant published in (18)] had similar protective efficacy with MF59like adjuvant but lower than that of PGA/Alum (unpublished data). We also observed that MF59-like adjuvant did not induce cell-mediated immunity against the influenza vaccine antigen by IFN- $\gamma$ ELISPOT assay but PGA/Alum robustly enhanced cell-mediated immunity (unpublished data). Therefore, we imply that PGA/Alum could act as a more potent adjuvant than MF59.

Activated DCs critically contribute to antigen processing and presentation. The activation of DCs and their delivery of antigen to LNs are crucial for the ability of a vaccine to effectively initiate innate and adaptive immune responses (41). Our results showed that PGA/Alum induces DC activation through TLR4 signaling, as assessed by increases in the levels of costimulatory molecules and pro-inflammatory cytokines, as well as enhancement of antigen processing. PGA/Alum robustly enhanced both antigen trafficking and the migration of antigen-loaded DCs from the injection sites to dLNs, which is 


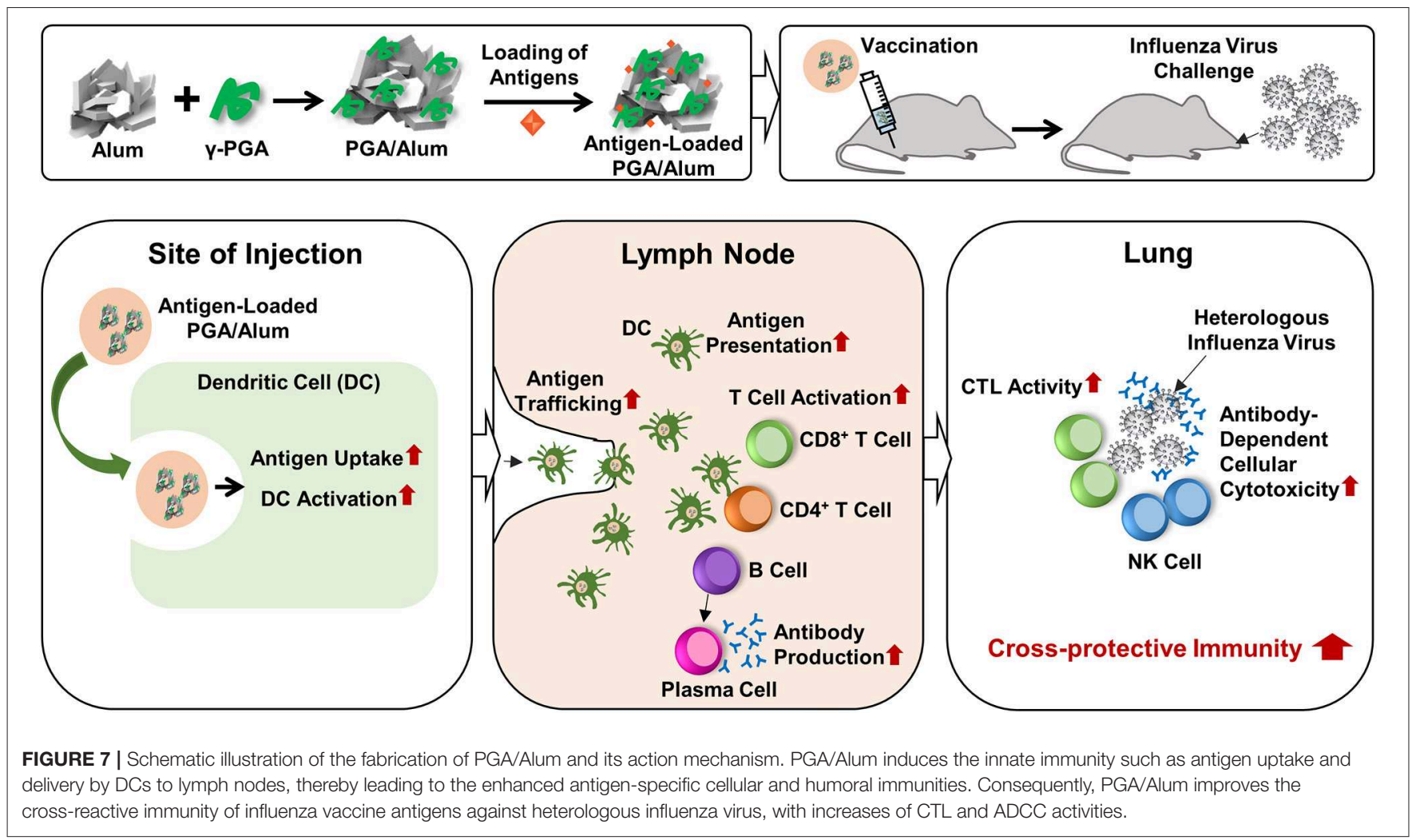

consistent with previous findings obtained with the MPL-based adjuvants, AS04 and AS01 (37, 38). Our immunofluorescent microscopic analysis further revealed that PGA/Alum increased antigen accumulation in the subcapsular, cortical, and medullary sinus regions of dLNs, indicating that antigen presentation in LNs could be facilitated by PGA/Alum. Circulating immature DCs reach inflamed tissues by following the chemoattractant gradient to uptake antigens and then migrate to dLNs to initiate adaptive immunity (29). Thus, it is relevant that PGA/Alum was found to robustly enhance not only the recruitment of DCs to injection sites and dLNs but also the migration of antigen-loaded DCs to dLNs. Consistent with previous studies in which mice were injected with other adjuvants, including AS04, AS01, and AS03 (37, 38, 42), PGA/Alum increased the levels of chemokines (MIP-1 $\alpha$, MIP-1 $\beta$, and MCP-1) at injection sites and dLNs. We also found that the expression of CCR7 on DCs, which is responsible for their migration to LNs, was increased by PGA/Alum. Notably, this has not been reported for AS04. Thus, the ability of PGA/Alum to enhance DC migration by increasing chemokine levels and CCR7 expression might provide insight into the action mechanisms of this vaccine adjuvant. Together, our findings demonstrate that PGA/Alum can act as a potent adjuvant capable of activating innate immune responses, including DC activation, DC migration, and antigen trafficking.

Our proof-of-concept experiments demonstrated that PGA/Alum efficiently enhances the humoral and cellular immune responses specific to both OVA (a model antigen) and the influenza vaccine antigen (a vaccine antigen of a representative infectious disease). Importantly, we found that PGA/Alum significantly increased ADCC, which has recently been shown to induce effective protection against various viruses, including Ebola (9), human immunodeficiency virus $(43,44)$, Epstein-Barr virus $(45)$, and influenza viruses $(8,32)$. Our results from an ADCC assay performed using mouse serum revealed that PGA/Alum enhanced ADCC activity. As ADCC is known to be initiated by the IgG2 subclass in mice (32), it is notable that we observed a significant induction of IgG2b in the sera of mice immunized with the antigen mixed with PGA/Alum. Because $\gamma$-PGA induces Th1 responses (17, 46-48), which are associated with the induction of IgG2b (49), our results suggest that $\gamma$-PGA acts synergistically with alum in PGA/Alum to elevate the production of IgG2b and thereby enhance ADCC.

Influenza A viruses exist as several subtypes, and new viruses can emerge due to point mutations (e.g., antigenic drift) or genetic reassortments between different viral subtypes (e.g., antigen shift), potentially leading to influenza epidemics and pandemics (50). The cross-reactivity of an influenza vaccine is essential for its ability to broadly protect against antigenically drifted influenza viruses. Our present results reveal that PGA/Alum enhanced the protective efficacy of the influenza $\mathrm{pH} 1 \mathrm{~N} 1$ vaccine against homologous virus. Importantly, PGA/Alum-adjuvanted pH1N1 vaccine exhibited improved cross-protection against both heterologous influenza virus (e.g., $\mathrm{H} 1 \mathrm{~N} 1$ ) and heterosubtypic virus (e.g., H3N2). In contrast, 
cross-protection was not observed in mice immunized with alum- or $\gamma$-PGA-adjuvanted $\mathrm{pH} 1 \mathrm{~N} 1$ vaccine. As cross-reactive immunity is primarily mediated by CTLs, which recognize broadly conserved epitopes shared by influenza A virus subtypes (50), our results indicate that PGA/Alum-adjuvanted $\mathrm{pH} 1 \mathrm{~N} 1$ vaccine drastically enhanced cross-reactive CTL activities against $\mathrm{H} 1 \mathrm{~N} 1$ and $\mathrm{H} 3 \mathrm{~N} 2$ viruses. In this experiment, we used a reassortant $\mathrm{H} 3 \mathrm{~N} 2$ virus carrying $\mathrm{HA}$ and $\mathrm{NA}$ genes from the A/Hong Kong/1/68 and internal genes from A/Puerto Rico/8/34. Cell mediated immunity against conservation of internal proteins may contribute to PGA/Alum-enhanced heterosubtypic protection. In addition, PGA/Alum enhanced ADCC, which is considered to be the crucial function of non-neutralizing Abs in cross-reactive immunity, and $\mathrm{pH} 1 \mathrm{~N} 1$ vaccine-PGA/Aluminduced sera Abs had cross-reactive ADCC activity against $\mathrm{H} 1 \mathrm{~N} 1$ and $\mathrm{H} 3 \mathrm{~N} 2$ viruses. Consistent with previous reports showing that ADCC-mediating Abs bind to the conserved HA stalk domain of the influenza virus $(10,51)$, PGA/Alum increased the level of the HA stalk Abs but not crossreactive neutralizing Abs of heterologous virus (Figure S12). In vivo cross-protection assay conferred that PGA/Alumenhanced heterosubtypic cross-protection may be mainly cellmediated and partially by humoral immunity, similar with a previous report (Figure S10) (52). Thus, PGA/Alum might help improve the protective efficacy and cross-protection of the influenza vaccine, and its use as an adjuvant could help resolve the limitations of the current influenza vaccines. Given that ADCC and CTL activities have been suggested to contribute to protecting elderly individuals against influenza virus infection (53, 54), our results suggest that PGA/Alum could be used as a vaccine adjuvant for older people with dysregulated immune responses. Taken together, our findings indicate that PGA/Alum may be a promising candidate as a vaccine adjuvant for preventing diseases caused by influenza viruses and other infectious agents.

\section{REFERENCES}

1. Ellenberg SS, Foulkes MA, Midthun K, Goldenthal KL. Evaluating the safety of new vaccines: summary of a workshop. Am J Public Health. (2005) 95:800-7. doi: 10.2105/AJPH.2004.039438

2. Moyer TJ, Zmolek AC, Irvine DJ. Beyond antigens and adjuvants: formulating future vaccines. J Clin Invest. (2016) 126:799-808. doi: 10.1172/JCI 81083

3. Nascimento IP, Leite LC. Recombinant vaccines and the development of new vaccine strategies. Braz J Med Biol Res. (2012) 45:1102-11. doi: 10.1590/S0100-879X2012007500142

4. Bar-On Y, Glasner A, Meningher T, Achdout H, Gur C, Lankry $\mathrm{D}$, et al. Neuraminidase-mediated, NKp46-dependent immuneevasion mechanism of influenza viruses. Cell Rep. (2013) 3:1044-50. doi: 10.1016/j.celrep.2013.03.034

5. Guy B. The perfect mix: recent progress in adjuvant research. Nat Rev Microbiol. (2007) 5:505-17. doi: 10.1038/nrmicrol681

6. Di Pasquale A, Preiss S, Tavares Da Silva F, Garcon N. Vaccine adjuvants: from 1920 to 2015 and beyond. Vaccines. (2015) 3:320-43. doi: $10.3390 /$ vaccines3020320

7. Reed SG, Orr MT, Fox CB. Key roles of adjuvants in modern vaccines. Nat Med. (2013) 19:1597-608. doi: 10.1038/nm.3409

\section{DATA AVAILABILITY}

The raw data supporting the conclusions of this manuscript will be made available by the authors, without undue reservation, to any qualified researcher.

\section{ETHICS STATEMENT}

All animal experiments were reviewed and approved by the Institutional Animal Care and Use Committee (IACUC) of the KRIBB and were performed according to the Guidelines for Animal Experiments of the KRIBB.

\section{AUTHOR CONTRIBUTIONS}

HP designed and supervised the experiments, analyzed results, and wrote the manuscript. QN, CK, JK, WL, and JY performed the experiments. QN, CK, and JY analyzed the experiments and drafted the manuscript. MS contributed to produce $\gamma$-PGA and discuss the results. WL and JJ contributed to analyze chemical characterization of the PGA/Alum.

\section{FUNDING}

This work was supported by the R\&D Convergence Program of National Research Council of Science and Technology (NST) of Republic of Korea (Grant no. CAP-16-02-KIST), and by the National Research Foundation of Korea (NRF) grant funded by the Korea government (Grant no. 2018M3A9H4055203).

\section{SUPPLEMENTARY MATERIAL}

The Supplementary Material for this article can be found online at: https://www.frontiersin.org/articles/10.3389/fimmu. 2019.01604/full\#supplementary-material

8. Jegaskanda S, Weinfurter JT, Friedrich TC, Kent SJ. Antibody-dependent cellular cytotoxicity is associated with control of pandemic H1N1 influenza virus infection of macaques. J Virol. (2013) 87:5512-22. doi: 10.1128/JVI.03030-12

9. Liu Q, Fan C, Li Q, Zhou S, Huang W, Wang L, et al. Antibodydependent-cellular-cytotoxicity-inducing antibodies significantly affect the post-exposure treatment of Ebola virus infection. Sci Rep. (2017) 7:45552. doi: $10.1038 /$ srep45552

10. Park SJ, Si YJ, Kim J, Song MS, Kim SM, Kim EH, et al. Cross-protective efficacies of highly-pathogenic avian influenza $\mathrm{H} 5 \mathrm{~N} 1$ vaccines against a recent H5N8 virus. Virology. (2016) 498:36-43. doi: 10.1016/j.virol.2016.08.010

11. Milligan C, Richardson BA, John-Stewart G, Nduati R, Overbaugh J. Passively acquired antibody-dependent cellular cytotoxicity (ADCC) activity in HIVinfected infants is associated with reduced mortality. Cell Host Microbe. (2015) 17:500-6. doi: 10.1016/j.chom.2015.03.002

12. Song JY, Cheong HJ, Noh JY, Seo YB, Choi WS, Cho GJ, et al. Long-term and cross-reactive immunogenicity of inactivated trivalent influenza vaccine in the elderly: MF59-adjuvanted vaccine versus unadjuvanted vaccine. J Med Virol. (2013) 85:1591-7. doi: 10.1002/jmv.23630

13. Sivakumar SM, Safhi MM, Kannadasan M, Sukumaran N. Vaccine adjuvants - current status and prospects on controlled release adjuvancity. Saudi Pharm J. (2011) 19:197-206. doi: 10.1016/j.jsps.2011.06.003 
14. Mosaheb MM, Reiser ML, Wetzler LM. Toll-like receptor ligand-based vaccine adjuvants require intact MyD88 signaling in antigen-presenting cells for germinal center formation and antibody production. Front Immunol. (2017) 8:225. doi: 10.3389/fimmu.2017.00225

15. Levitz SM, Golenbock DT. Beyond empiricism: informing vaccine development through innate immunity research. Cell. (2012) 148:1284-92. doi: 10.1016/j.cell.2012.02.012

16. Sung MH, Park C, Kim CJ, Poo H, Soda K, Ashiuchi M. Natural and edible biopolymer poly-gamma-glutamic acid: synthesis, production, and applications. Chem Rec. (2005) 5:352-66. doi: 10.1002/tcr.20061

17. Lee TY, Kim YH, Yoon SW, Choi JC, Yang JM, Kim CJ, et al. Oral administration of poly-gamma-glutamate induces TLR4- and dendritic celldependent antitumor effect. Cancer Immunol Immunother. (2009) 58:178194. doi: 10.1007/s00262-009-0689-4

18. Yang J, Shim SM, Nguyen TQ, Kim EH, Kim K, Lim YT, et al. Polygamma-glutamic acid/chitosan nanogel greatly enhances the efficacy and heterosubtypic cross-reactivity of H1N1 pandemic influenza vaccine. Sci Rep. (2017) 7:44839. doi: 10.1038/srep44839

19. Lim YT, Shim SM, Noh YW, Lee KS, Choi DY, Uyama H, et al. Bioderived polyelectrolyte nanogels for robust antigen loading and vaccine adjuvant effects. Small. (2011) 7:3281-6. doi: 10.1002/smll.201101836

20. Reed LJ, Muench H. A simple method for estimating fifty percent endpoint. Am J Hygiene. (1938) 27:493-97. doi: 10.1093/oxfordjournals.aje. a1 18408

21. Mold M, Shardlow E, Exley C. Insight into the cellular fate and toxicity of aluminium adjuvants used in clinically approved human vaccinations. Sci Rep. (2016) 6:31578. doi: 10.1038/srep31578

22. Schärtl W. Light Scattering From Polymer Solutions and Nanoparticle Dispersions. Berlin: Springer Science \& Business Media (2007).

23. Li Z, He G, Hua J, Wu M, Guo W, Gong J, et al. Preparation of $\gamma$-PGA hydrogels and swelling behaviors in salt solutions with different ionic valence numbers. RSC Adv. (2017) 7:11085-93. doi: 10.1039/C6RA26419K

24. Zhao J, Shi H, Liu M, Lu J, Li W. Coagulation-adsorption of reactive orange from aqueous solution by freshly formed magnesium hydroxide: mixing time and mechanistic study. Water Sci Technol. (2017) 75:1776-83. doi: 10.2166/wst.2017.037

25. Kamaraj R, Vasudevan S. Facile one-pot electrosynthesis of $\mathrm{Al}$ $(\mathrm{OH})$ 3-kinetics and equilibrium modeling for adsorption of 2:4:5trichlorophenoxyacetic acid from aqueous solution. $N$ J Chem. (2016) 40:2249-58. doi: 10.1039/C5NJ02407B

26. Balakrishnan H, Hassan A, Isitman NA, Kaynak C. On the use of magnesium hydroxide towards halogen-free flame-retarded polyamide6/polypropylene blends. Polymer Degrad Stabil. (2012) 97:1447-57. doi: 10.1016/j.polymdegradstab.2012.05.011

27. Merad M, Sathe P, Helft J, Miller J, Mortha A. The dendritic cell lineage: ontogeny and function of dendritic cells and their subsets in the steady state and the inflamed setting. Annu Rev Immunol. (2013) 31:563-604. doi: 10.1146/annurev-immunol-020711-074950

28. Alvarez D, Vollmann EH, von Andrian UH. Mechanisms and consequences of dendritic cell migration. Immunity. (2008) 29:325-42. doi: 10.1016/j.immuni.2008.08.006

29. Sallusto F, Lanzavecchia A. Understanding dendritic cell and T-lymphocyte traffic through the analysis of chemokine receptor expression. Immunol Rev. (2000) 177:134-40. doi: 10.1034/j.1600-065X.2000.17717.x

30. Sozzani S, Allavena P, Vecchi A, Mantovani A. The role of chemokines in the regulation of dendritic cell trafficking. J Leukoc Biol. (1999) 66:1-9. doi: 10.1002/jlb.66.1.1

31. Forster R, Schubel A, Breitfeld D, Kremmer E, Renner-Muller I, Wolf E, et al. CCR7 coordinates the primary immune response by establishing functional microenvironments in secondary lymphoid organs. Cell. (1999) 99:23-33. doi: 10.1016/S0092-8674(00)80059-8

32. Jegaskanda S, Reading PC, Kent SJ. Influenza-specific antibody-dependent cellular cytotoxicity: toward a universal influenza vaccine. J Immunol. (2014) 193:469-75. doi: 10.4049/jimmunol.1400432

33. Seidel UJ, Schlegel P, Lang P. Natural killer cell mediated antibody-dependent cellular cytotoxicity in tumor immunotherapy with therapeutic antibodies. Front Immunol. (2013) 4:76. doi: 10.3389/fimmu.2013.00076
34. Quan FS, Compans RW, Nguyen HH, Kang SM. Induction of heterosubtypic immunity to influenza virus by intranasal immunization. J Virol. (2008) 82:1350-9. doi: 10.1128/JVI.01615-07

35. Kim MC, Song JM, O E, Kwon YM, Lee YJ, et al. Virus-like particles containing multiple M2 extracellular domains confer improved crossprotection against various subtypes of influenza virus. Mol Ther. (2013) 21:485-92. doi: 10.1038/mt.2012.246

36. DiLillo DJ, Tan GS, Palese P, Ravetch JV. Broadly neutralizing hemagglutinin stalk-specific antibodies require FcgammaR interactions for protection against influenza virus in vivo. Nat Med. (2014) 20:143-51. doi: 10.1038/nm.3443

37. Didierlaurent AM, Collignon C, Bourguignon P, Wouters S, Fierens K, Fochesato $\mathrm{M}$, et al. Enhancement of adaptive immunity by the human vaccine adjuvant AS01 depends on activated dendritic cells. J Immunol. (2014) 193:1920-30. doi: 10.4049/jimmunol.1400948

38. Didierlaurent AM, Morel S, Lockman L, Giannini SL, Bisteau M, Carlsen H, et al. AS04, an aluminum salt- and TLR4 agonist-based adjuvant system, induces a transient localized innate immune response leading to enhanced adaptive immunity. J Immunol. (2009) 183:6186-97. doi: 10.4049/jimmunol.0901474

39. Black S, Della Cioppa G, Malfroot A, Nacci P, Nicolay U, Pellegrini M, et al. Safety of MF59-adjuvanted versus non-adjuvanted influenza vaccines in children and adolescents: an integrated analysis. Vaccine. (2010) 28:7331-6. doi: 10.1016/j.vaccine.2010.08.075

40. Stassijns J, Bollaerts K, Baay M, Verstraeten T. A systematic review and metaanalysis on the safety of newly adjuvanted vaccines among children. Vaccine. (2016) 34:714-22. doi: 10.1016/j.vaccine.2015.12.024

41. Macri C, Dumont C, Johnston AP, Mintern JD. Targeting dendritic cells: a promising strategy to improve vaccine effectiveness. Clin Transl Immunology. (2016) 5:e66. doi: 10.1038/cti.2016.6

42. Morel S, Didierlaurent A, Bourguignon P, Delhaye S, Baras B, Jacob V, et al. Adjuvant System AS03 containing alpha-tocopherol modulates innate immune response and leads to improved adaptive immunity. Vaccine. (2011) 29:2461-73. doi: 10.1016/j.vaccine.2011.01.011

43. Smalls-Mantey A, Doria-Rose N, Klein R, Patamawenu A, Migueles SA, Ko S-Y, et al. Antibody-dependent cellular cytotoxicity against primary HIV-infected CD4+ $\mathrm{T}$ cells is directly associated with the magnitude of surface IgG binding. J Virol. (2012) 86:8672-80. doi: 10.1128/JVI. 00287-12

44. Chung AW, Navis M, Isitman G, Centre R, Finlayson R, Bloch M, et al. Activation of NK cells by ADCC responses during early HIV infection. Viral Immunol. (2011) 24:171-5. doi: 10.1089/vim.2010. 0108

45. Lai J, Choo JAL, Tan WJ, Too CT, Oo MZ, Suter MA, et al. TCRlike antibodies mediate complement and antibody-dependent cellular cytotoxicity against Epstein-Barr virus-transformed B lymphoblastoid cells expressing different HLA-A* 02 microvariants. Sci Rep. (2017) 7:9923 doi: 10.1038/s41598-017-10265-6

46. Uto T, Akagi T, Yoshinaga K, Toyama M, Akashi M, Baba M. The induction of innate and adaptive immunity by biodegradable poly(gamma-glutamic acid) nanoparticles via a TLR4 and MyD88 signaling pathway. Biomaterials. (2011) 32:5206-12. doi: 10.1016/j.biomaterials.2011.03.052

47. Kim EH, Choi YK, Kim CJ, Sung MH, Poo H. Intranasal administration of poly-gamma glutamate induced antiviral activity and protective immune responses against H1N1 influenza A virus infection. Virol J. (2015) 12:160 doi: 10.1186/s12985-015-0387-0

48. Kim TW, Lee TY, Bae HC, Hahm JH, Kim YH, Park C, et al. Oral administration of high molecular mass poly-gamma-glutamate induces NK cell-mediated antitumor immunity. J Immunol. (2007) 179:775-80. doi: 10.4049/jimmunol.179.2.775

49. Germann T, Bongartz M, Dlugonska H, Hess H, Schmitt E, Kolbe L, et al. Interleukin-12 profoundly up-regulates the synthesis of antigen-specific complement-fixing IgG2a, IgG2b and IgG3 antibody subclasses in vivo. Eur J Immunol. (1995) 25:823-9. doi: 10.1002/eji.1830250329

50. Boon AC, de Mutsert G, van Baarle D, Smith DJ, Lapedes AS, Fouchier RA, et al. Recognition of homo- and heterosubtypic variants of influenza A viruses by human CD8+ T lymphocytes. J Immunol. (2004) 172:2453-60. doi: 10.4049 /jimmunol.172.4.2453 
51. He W, Tan GS, Mullarkey CE, Lee AJ, Lam MM, Krammer F, et al. Epitope specificity plays a critical role in regulating antibody-dependent cell-mediated cytotoxicity against influenza A virus. Proc Natl Acad Sci USA. (2016) 113:11931-36. doi: 10.1073/pnas.1609316113

52. Schwartzman LM, Cathcart AL, Pujanauski LM, Qi L, Kash JC, Taubenberger JK. An intranasal virus-like particle vaccine broadly protects mice from multiple subtypes of influenza A virus. MBio. (2015) 6:e01044. doi: 10.1128/mBio.01044-15

53. Deng Y, Jing Y, Campbell AE, Gravenstein S. Age-related impaired type $1 \mathrm{~T}$ cell responses to influenza: reduced activation ex vivo, decreased expansion in CTL culture in vitro, and blunted response to influenza vaccination in vivo in the elderly. I Immunol. (2004) 172:3437-46. doi: 10.4049/jimmunol.172.6.3437

54. Jegaskanda S, Laurie KL, Amarasena TH, Winnall WR, Kramski M, De Rose R, et al. Age-associated cross-reactive antibody-dependent cellular cytotoxicity toward 2009 pandemic influenza A virus subtype H1N1. J Infect Dis. (2013) 208:1051-61. doi: 10.1093/infdis/ jit294

Conflict of Interest Statement: The authors declare that the research was conducted in the absence of any commercial or financial relationships that could be construed as a potential conflict of interest.

Copyright (c) 2019 Nguyen, Kwak, Lee, Kim, Jeong, Sung, Yang and Poo. This is an open-access article distributed under the terms of the Creative Commons Attribution License (CC BY). The use, distribution or reproduction in other forums is permitted, provided the original author(s) and the copyright owner(s) are credited and that the original publication in this journal is cited, in accordance with accepted academic practice. No use, distribution or reproduction is permitted which does not comply with these terms. 